\title{
Essential Fatty Acids and Their Metabolites in the Pathobiology of Inflammation and Its Resolution
}

\author{
Undurti N Das ${ }^{1,2}$
}

Citation: Das, U.N. Essential Fatty Acids and Their Metabolites in the Pathobiology of Inflammation and Its Resolution. Biomolecules 2021, 11, 1873. https://doi.org/10.3390/ biom 11121873

Academic Editor: Irene Faenza

Received: 4 November 2021 Accepted: 9 December 2021 Published: 14 December 2021

Publisher's Note: MDPI stays neutral with regard to jurisdictional claims in published maps and institutional affiliations.

Copyright: (C) 2021 by the author. Licensee MDPI, Basel, Switzerland. This article is an open access article distributed under the terms and conditions of the Creative Commons Attribution (CC BY) license (https:/ / creativecommons.org/licenses/by/ $4.0 /)$.
1 UND Life Sciences, 2221 NW 5th St., Battle Ground, WA 98604, USA; undurti@hotmail.com or undurti@lipidworld.com; Tel.: +1-508-904-5376

2 International Research Centre, Biotechnologies of the Third Millennium, ITMO University, Saint Petersburg 191002, Russia

\begin{abstract}
Arachidonic acid (AA) metabolism is critical in the initiation and resolution of inflammation. Prostaglandin E2 (PGE2) and leukotriene B4/D4/E4 (LTB4/LD4/LTE4), derived from AA, are involved in the initiation of inflammation and regulation of immune response, hematopoiesis, and M1 (pro-inflammatory) macrophage facilitation. Paradoxically, PGE2 suppresses interleukin-6 (IL-6) and tumor necrosis factor- $\alpha$ (TNF- $\alpha$ ) production and triggers the production of lipoxin A4 (LXA4) from AA to initiate inflammation resolution process and augment regeneration of tissues. LXA4 suppresses PGE2 and LTs' synthesis and action and facilitates M2 macrophage generation to resolve inflammation. AA inactivates enveloped viruses including SARS-CoV-2. Macrophages, NK cells, T cells, and other immunocytes release AA and other bioactive lipids to produce their anti-microbial actions. AA, PGE2, and LXA4 have cytoprotective actions, regulate nitric oxide generation, and are critical to maintain cell shape and control cell motility and phagocytosis, and inflammation, immunity, and anti-microbial actions. Hence, it is proposed that AA plays a crucial role in the pathobiology of ischemia/reperfusion injury, sepsis, COVID-19, and other critical illnesses, implying that its (AA) administration may be of significant benefit in the prevention and amelioration of these diseases.
\end{abstract}

Keywords: SARS-CoV-2; COVID-19; polyunsaturated fatty acids; arachidonic acid; prostaglandins; lipoxin A4; resolvins; protectins; maresins; inflammation; ARDS

\section{Introduction}

Inflammation and its timely resolution are essential for health and disease, especially to recover from microbial infections, injury, and surgery. Some of the serious illnesses in which inflammation plays a critical role include ischemia/reperfusion injury, sepsis, ARDS (acute respiratory distress syndrome), post-surgical sepsis/shock, and cytokine storm seen in patients with COVID-19. In all these conditions, acute inflammation goes unabated due to excess production of pro-inflammatory cytokines, prostaglandins, leukotrienes, bradykinin, and reactive oxygen species (ROS). In addition, there could occur concomitant deficiency of anti-inflammatory cytokines and lipid mediators. Severe COVID-19 (coronavirus disease 2019) caused by SARS-CoV-2, can cause ARDS because of damage to endothelial cells of various blood vessels, especially pulmonary vessels resulting in endotheliopathy, alveolar exudative inflammation and interstitial inflammation, alveolar epithelium proliferation, and hyaline membrane formation. One of the best examples of critical illnesses is COVID-19, which is associated with the excess production of the proinflammatory cytokines interleukin-6 (IL-6), tumor necrosis factor- $\alpha$ (TNF- $\alpha$, ) and other cytokines. COVID-19 has been shown to affect almost all vital organs in the body from head to toe including respiratory, cardiovascular, gut, renal, central nervous, immune, and coagulation systems. Respiratory failure that may occur in those with severe COVID-19 calls for invasive respiratory support and antithrombotic measures. In this review, COVID-19 is discussed in detail as an example of the severe critical illnesses and inflammatory and immune changes that occur in it and other illnesses such as ischemia/reperfusion injury, sepsis, 
and ARDS and the potential role of bioactive lipids and their pro- and anti-inflammatory metabolites. Based on this evidence, it is suggested that AA and its metabolites may have a therapeutic role in the prevention and management of ischemia/reperfusion injury, sepsis, COVID-19, ARDS, and other critical illnesses, with emphasis on COVID-19.

\section{SARS-CoV-2 and COVID-19}

The SARS-CoV-2 virus binds to the angiotensin-converting enzyme 2 (ACE2) receptor expressed by nasal and bronchial epithelial cells and pneumocytes by the ability of its spike (S) protein to bind to the same (ACE2). The type 2 transmembrane serine protease (TMPRSS2) of the host cell can cleave ACE2 and activate the S protein and promote SARSCoV-2 virus uptake into the host cells [1]. Both ACE2 and TMPRSS2 need to be expressed by the host target cells including the alveolar epithelial type II and vascular endothelial cells so that SARS-CoV-2 can infect and induce inflammatory reaction, leading to the influx of inflammatory cells such as monocytes and neutrophils that, in turn, release proinflammatory cytokines (IL-1, IL-6, TNF- $\alpha$, HMGB1, etc.) and reactive oxygen species [2]. These events lead to ground-glass opacities on computed tomography (CT) and pulmonary edema of alveolar spaces with hyaline membrane formation that leads to ARDS. In addition to pro-inflammatory cytokines, a potential role of bradykinin has been proposed in these features [3]. Thus, COVID-19 is characterized by endothelial barrier disruption, alveolarcapillary oxygen transmission dysfunction, impaired oxygen capacity diffusion, diffuse intravascular coagulation and pulmonary microthrombi, and a high incidence of thrombotic complications including deep venous thrombosis, pulmonary embolism, and arterial thrombosis that can result in limb ischemia, ischemic stroke, and myocardial infarction.

COVID-19 is like other respiratory viral diseases such as influenza and infects and induces apoptosis of T lymphocytes to induce severe lymphopenia and impair lymphopoiesis partly due to a striking reduction in Bcl-6+ germinal center B cells that correlate with an early specific block in Bcl-6+ TFH cell differentiation associated with an increase in Tbet+ TH1 cells and aberrant extrafollicular TNF- $\alpha$ accumulation in the spleen and lymph nodes [4]. These results suggest that the high TNF- $\alpha$ levels seen in severe COVID-19 not only cause a so-called 'cytokine storm', which is now rather controversial [5], but also suppress immune response, leading to a lack of type I IFNs, reduced HLA-DR in the myeloid cells, and transient expression of IFN-stimulated genes [6,7]. Since developing specific anti-SARS-CoV-2 compounds and vaccine(s) is time consuming, especially when the SARS-CoV-2 is mutating, making it resistant/unresponsive/less responsive to the vaccines that have been developed, it is important to develop alternative strategies to inactivate the virus and prevent or ameliorate inflammatory events that are associated with SARS-CoV-2 infection. I propose that arachidonic acid (AA, 20:4 n-6), a precursor of pro-inflammatory prostaglandin E2 (PGE2) and anti-inflammatory lipoxin A4 (LXA4), and other bioactive lipids have a significant role not only in the pathobiology of COVID-19 but also in sepsis, ischemia-reperfusion injury, autoimmune arthritis (and possibly, in lupus), and in their prevention and management.

\section{EFAs' (Essential Fatty Acids') Metabolism}

Dietary EFAs' cis-linoleic acid (LA, 18:2 n-6) and $\alpha$-linolenic acid (ALA, 18:3 n-3) are widely distributed in our diet and, hence, their deficiency is rare in humans. LA is metabolized by delta-6- desaturase and delta-5- desaturase and elongases to convert it to $\gamma$ linoleic acid (GLA, 18:3 n-6), dihomo-GLA (DGLA, 20:3 n-6), and arachidonic acid (AA, 20:4 n-6), whereas ALA gives rise to eicosapentaenoic acid EPA, 20:5 n-3, and docosahexaenoic acid (DHLA, 22:6 n-3) (see Figure 1 for metabolism of EFAs). Despite the proposal that both LA and ALA are metabolized by the same set of desaturases (delta-6-desaturase and delta-5-desaturase), there is indirect evidence that isoforms of desaturases may exist that may metabolize LA and ALA differently. This may explain why, under some specific conditions, GLA, DGLA, and AA levels are decreased but EPA and DHA may not show a similar degree of decrease or may, in fact, be increased. Hence, particular attention 
needs to be applied in interpreting the plasma and/or tissue levels of changes in EFAs and their metabolites in several diseases. For instance, it was reported that in Yoshida hepatoma cells, a drastic reduction in the concentrations of AA was noted with little or no change in DHA (see Table 1). If the same desaturases were to be acting on both LA and ALA to form their long-chain metabolites, one would expect the same degree of decrease in the concentrations of AA and DHA. However, this was not the case [8]. Similarly, the concentrations of n-6 fatty acids, especially GLA, DGLA, and AA, were found to be decreased to a greater degree compared to n-3 fatty acids such as EPA and DHA in those with type 2 diabetes mellitus (T2DM), hypertension (HTN), diabetic nephropathy (DN), and coronary heart disease (CHD) (see Table 2) [9]. This once again supports the contention that there could occur isoenzymes of desaturases. This suggestion applies to the changes observed in the plasma and tissue levels of their products such as prostaglandins (PGs), leukotrienes (LTs), thromboxanes (TXs), lipoxins (LXs), resolvins (RSVs), protectins (PRTs), and maresins (MaRs). These desaturases are the rate-limiting steps in the metabolism of LA and ALA. It is noteworthy that several co-factors are needed for adequate activity of desaturases. Some of these factors include magnesium; insulin; vitamins C, B1, B6, and B12; and folic acid, whereas high glucose inhibits their activity. DGLA is the precursor of 1 series prostaglandins (PGs) such as PGE1, whereas AA is the precursor of 2 series of PGs, thromboxanes (TXs), and 4 series leukotrienes (LTs), while 3 series PGs, TXs, and 5 series LTs are derived from EPA. Most of these PGs, TXs, and LTs are pro-inflammatory in nature. It is noteworthy that 2 series PGs, TXs, and 4 series LTs are more pro-inflammatory in nature compared to 3 series PGs, TXs, and 5 series LTs. Thus, PGE2 is more potent compared to PGE3 in inducing inflammatory events [10-12]. PGE1 derived from DGLA has significant anti-inflammatory actions [10].

Table 1. Content of fatty acids in normal liver and hepatoma cells and in microsomal suspensions from normal liver and Yoshida hepatoma cells. All values of mean \pm S. E.

\begin{tabular}{ccccc}
\hline $\begin{array}{c}\text { Measurement } \\
\text { (Fatty Acid) }\end{array}$ & $\begin{array}{c}\text { Normal Intact } \\
\text { Liver }\end{array}$ & $\begin{array}{c}\text { Intact Yoshida } \\
\text { Cells }\end{array}$ & $\begin{array}{c}\text { Normal Liver } \\
\text { Microsomes }\end{array}$ & $\begin{array}{c}\text { Yoshida } \\
\text { Microsomes }\end{array}$ \\
\hline 20:4 (AA) & $16.7 \pm 2.4$ & $8.7 \pm 0.7$ & $19.1 \pm 2.4$ & $9.6 \pm 0.8$ \\
22:6 (DHA) & $6.3 \pm 0.2$ & $5.2 \pm 0.6$ & $6.1 \pm 0.3$ & $5.3 \pm 0.4$ \\
\hline
\end{tabular}

Table 2. The percentage of distribution of fatty acids from plasma phospholipid fraction in patients with hypertension (HTN), coronary heart disease (CHD), type 2 diabetes mellitus, and diabetic nephropathy that are common with advanced age.

\begin{tabular}{cccccc}
\hline Fatty Acid & Control & HTN & CHD & Type 2 DM & $\begin{array}{c}\text { Diabetic } \\
\text { Nephropathy }\end{array}$ \\
\hline $18: 2$ n-6 (LA) & $18.6 \pm 3.1$ & $14.5 \pm 3.1^{*}$ & $17.8 \pm 5.0$ & $13.9 \pm 5.3$ & $15.1 \pm 3.1$ \\
\hline $18: 3$ n-6 (GLA) & $0.14 \pm 0.1$ & $0.4 \pm 0.3^{*}$ & $0.1 \pm 0.1^{*}$ & $0.2 \pm 0.3$ & $0.1 \pm 0.2$ \\
\hline $20: 3$ n-6 (DGLA) & $3.4 \pm 1.0$ & $3.1 \pm 0.9$ & $2.7 \pm 1.1$ & $1.7 \pm 1.0^{*}$ & $2.0 \pm 0.8^{*}$ \\
\hline $20: 4$ n-6 (AA) & $9.4 \pm 1.8$ & $7.8 \pm 2.0 *$ & $7.0 \pm 2.1 *$ & $4.6 \pm 1.8^{*}$ & $6.6 \pm 2.6^{*}$ \\
\hline $22: 5$ n-6 & $0.7 \pm 0.4$ & $0.4 \pm 0.4 *$ & $1.0 \pm 0.9$ & $2.1 \pm 0.6^{*}$ & $1.3 \pm 0.5^{*}$ \\
\hline $20: 4$ n-6/18:2 n-6 & 0.51 & 0.54 & 0.39 & 0.33 & 0.43 \\
\hline $18: 3$ n-3 (ALA) & $0.2 \pm 0.1$ & $0.4 \pm 0.2 *$ & $0.3 \pm 0.5$ & $0.1 \pm 0.2^{*}$ & $0.1 \pm 0.1 *$ \\
\hline $20: 5$ n-3 (EPA) & $0.4 \pm 0.4$ & $0.6 \pm 0.6$ & $0.1 \pm 0.2 *$ & $0.3 \pm 0.3$ & $0.2 \pm 0.3$ \\
\hline $22: 5$ n-3 & $0.5 \pm 0.2$ & $0.4 \pm 0.5$ & $0.3 \pm 0.3 *$ & $1.6 \pm 1.3$ & $1.7 \pm 1.1$ \\
\hline $22: 6$ n-3 (DHA) & $1.4 \pm 0.5$ & $1.2 \pm 0.6$ & $0.8 \pm 0.4 *$ & $0.5 \pm 0.4 *$ & $0.5 \pm 0.3 *$ \\
\hline $20: 5$ n-3/18:3 n-3 & 1.8 & 1.39 & 0.41 & 3.2 & 4.0 \\
\hline
\end{tabular}

All values are expressed as mean \pm S. D. ${ }^{*} p<0.05$ compared to control. These data are taken from ref. [9]. 


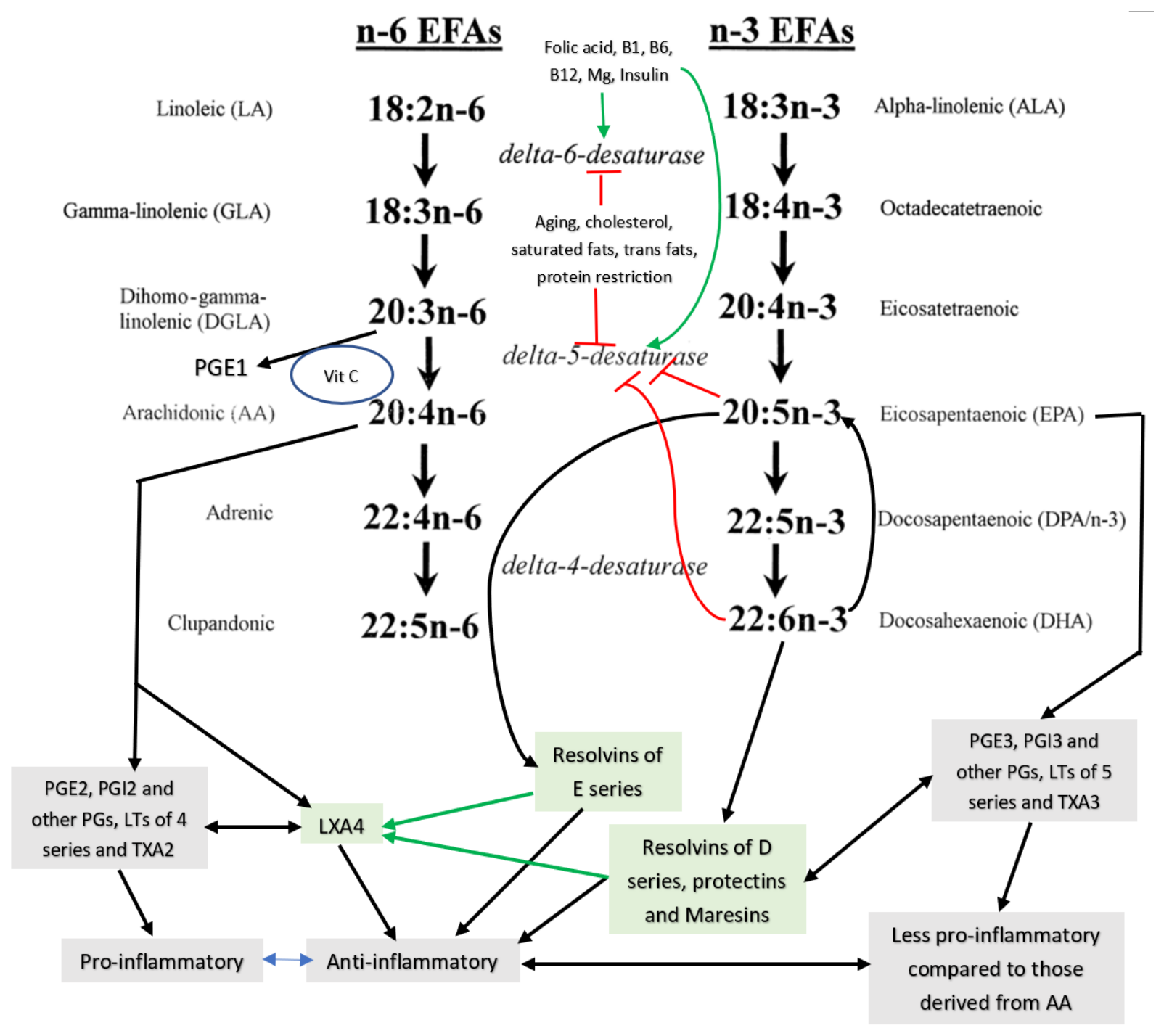

Figure 1. Metabolism of essential fatty acids (EFAs).

4. Interaction among Various EFAs and Their Pro- and Anti-Inflammatory Metabolites

LXA4 (lipoxin A4), a potent anti-inflammatory molecule, is derived from AA. Similar anti-inflammatory molecules, E series resolvins, are derived from EPA, whereas resolvins of D series, protectins, and maresins are formed from DHA [10]. The fact that both proand anti-inflammatory molecules are derived from the same precursors (especially AA and EPA) indicates that there could occur a positive and negative feedback regulation among them, a balance that may play a critical role in the regulation of inflammation in various conditions. It is noteworthy that pro-inflammatory PGs of 2 series and LTs of 4 series derived from AA are more potent compared to PGs of 3 series and LTs of 5 series derived from EPA. By the same token, it is interesting that LXA4 appears to be more potent than resolvins, protectins, and maresins derived from EPA and DHA [8,10]. In addition, there is a crosstalk among various PGs, LTs, LXA4, resolvins, protectins, and maresins. For instance, LXA4 inhibits the production of PGE2 and LTs, a mechanism by which it behaves as an anti-inflammatory compound. PGE1, PGE2, LXA4, resolvins, protectins, and maresins inhibit the production of pro-inflammatory cytokines especially interlukin-6 (IL-6) and tumor necrosis factor- $\alpha$ (TNF- $\alpha$ ). Our studies revealed that, in all probability, LXA4 is more potent in suppressing the production of IL- 6 and TNF- $\alpha$ compared to resolvins and protectins, especially in streptozotocin-induced type 1 and type 2 diabetic models [13-15]. In these studies [13-15], it was noted that when the same 
concentrations of LXA4 and resolvins were employed, the amount of decrease in plasma IL- 6 and TNF- $\alpha$ concentrations was more impressive in LXA4-treated animals compared to those treated with resolvins, implying that the former (LXA4) is more potent in bringing about its anti-inflammatory action compared to the latter (LXA4 > resolvins). Hence, it is reasonable to suggest that LXA4 is more potent than resolvins, protectins, and maresins in suppressing inflammation. It is interesting to note that both resolvin D1 and E1, derived from DHA and EPA, respectively, enhance the production of LXA4 (see Figures 2-4) (see references [14-16]), implying that, to some extent, resolvins (and probably protectins and maresins) bring about their anti-inflammatory actions by enhancing the formation of LXA4 that is derived from AA. It is noteworthy that administration of AA enhanced LXA4 formation both in vitro and in vivo (see Figures 5-7) and suppressed the expression of pro-inflammatory genes such as NF-kB and lipocalin $[13,17]$. It is of considerable interest to note that other fatty acids such as GLA, EPA, and DHA enhanced the production of LXA4 from pancreatic beta cells in vitro that was suppressed by alloxan treatment (see Figure 5). Although the exact mechanism by which these fatty acids enhance LXA4 formation is not clear, it may, partly, be by their ability to displace AA from the cell membrane lipid pool. These results attest to the proposal that there is a close interaction between $n-6$ and n-3 fatty acids and their metabolism (see Figure 1).
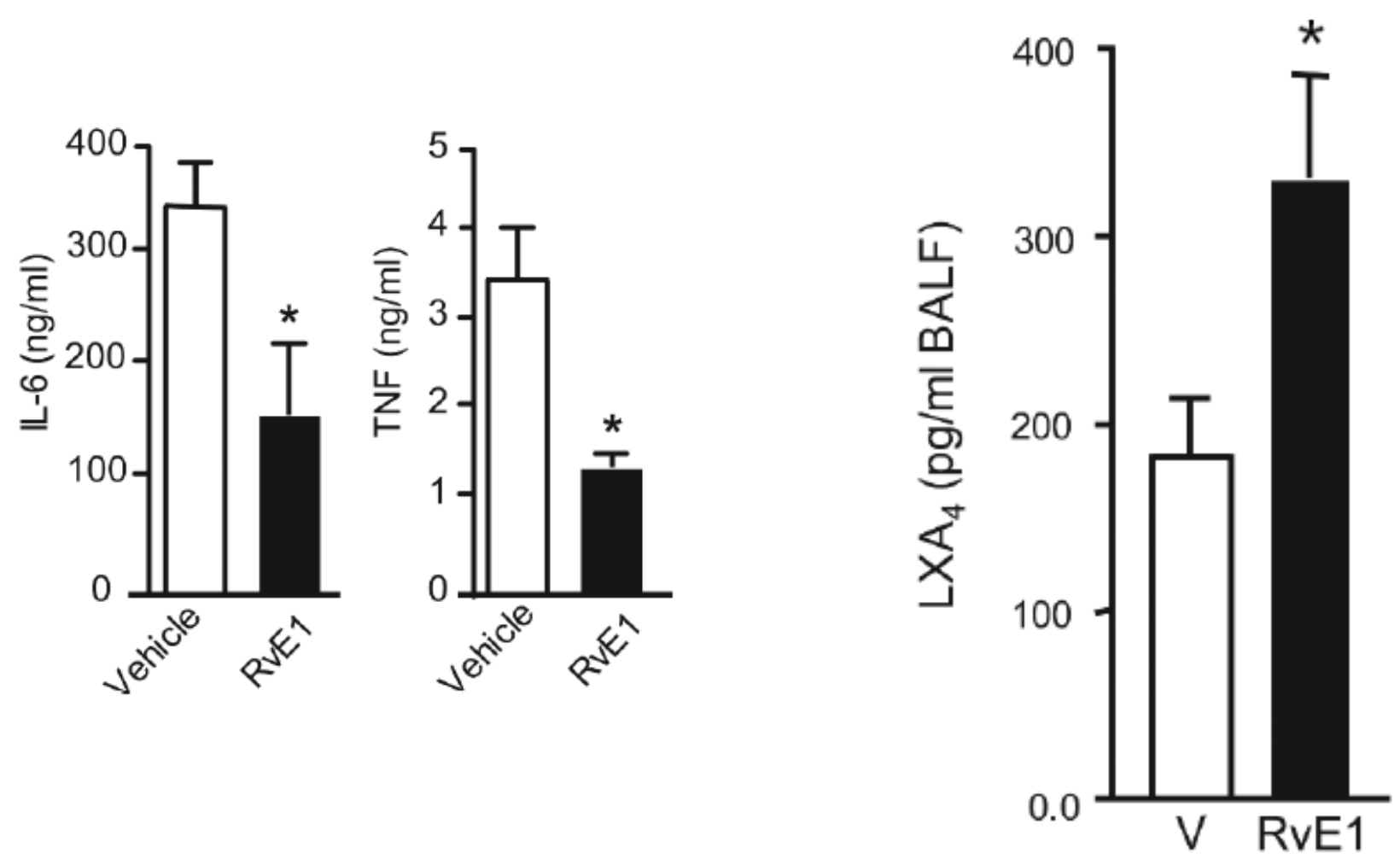

Figure 2. Effect of resolvin E1 on IL-6 and TNF- $\alpha$ levels and LXA4 formation in bronchial alveolar fluid in animals with allergic airway inflammation (taken from Ref. [16]). ${ }^{*} p<0.05$ compared to vehicle (V). In this study, the animals received 50 or $100 \mathrm{ng} /$ day intravenously. 
A

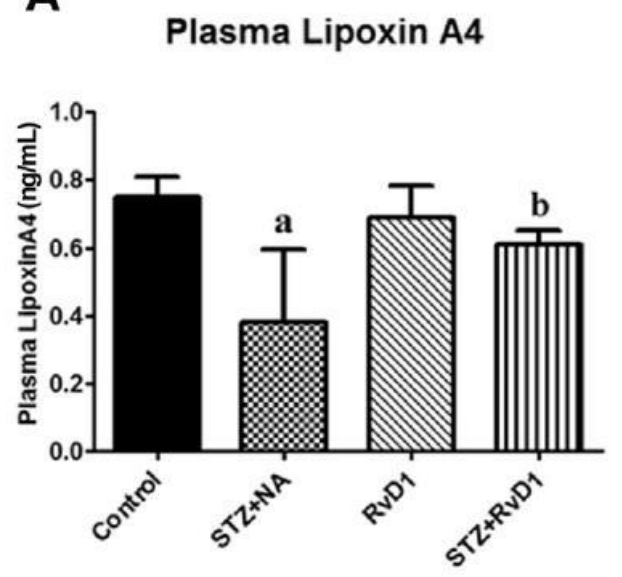

B

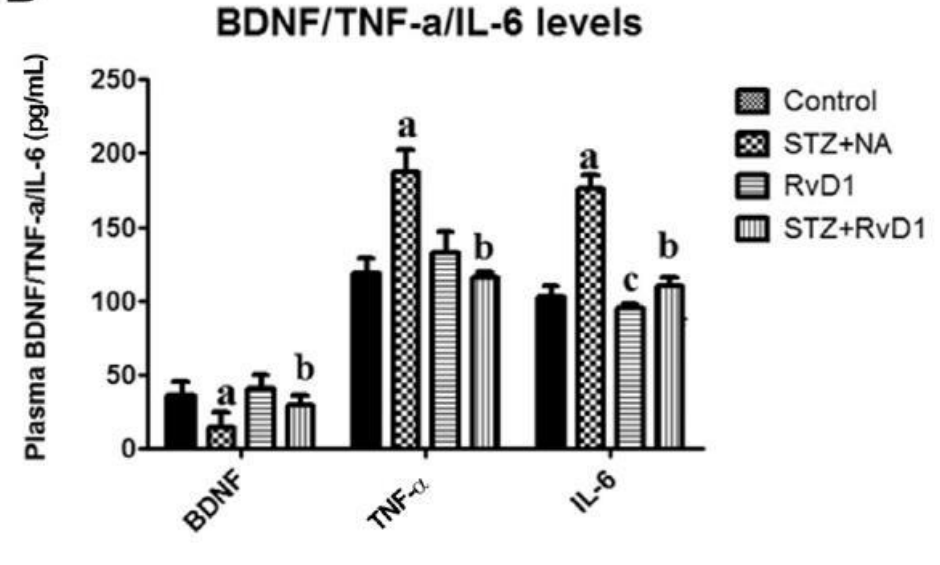

Figure 3. Effect of resolvin D1 (60 ng/animal by intraperitoneal route) on STZ-induced type 2 diabetes mellitus. Resolvin D1 not only abrogated STZ-induced diabetes but also suppressed STZ-induced increase in plasma IL- 6 and TNF- $\alpha$ levels and restored plasma LXA4 and BDNF to normal (these data are taken from ref. [14]). (A) ${ }^{\mathrm{a}} p \leq 0.001$ compared to untreated control; ${ }^{\mathrm{b}} p \leq 0.01$ compared to streptozotocin + nicotinamide (STZ + NA) group. (B) ${ }^{\mathrm{a}} p \leq 0.01$ compared to STZ + NA, and ${ }^{\mathrm{b}} p \leq 0.01$ compared to untreated control. TNF- $\alpha$ studies, ${ }^{\mathrm{a}} p \leq 0.01$ compared to control, and ${ }^{\mathrm{b}} p \leq 0.05$ compared to STZ + NA. IL-6 studies; ${ }^{\mathrm{a}} p \leq 0.01$ and ${ }^{\mathrm{c}} p \leq 0.01$ compared to control. ${ }^{\mathrm{b}} p \leq 0.01$ compared to STZ + NA group. All values are expressed as mean \pm SEM.

(A)

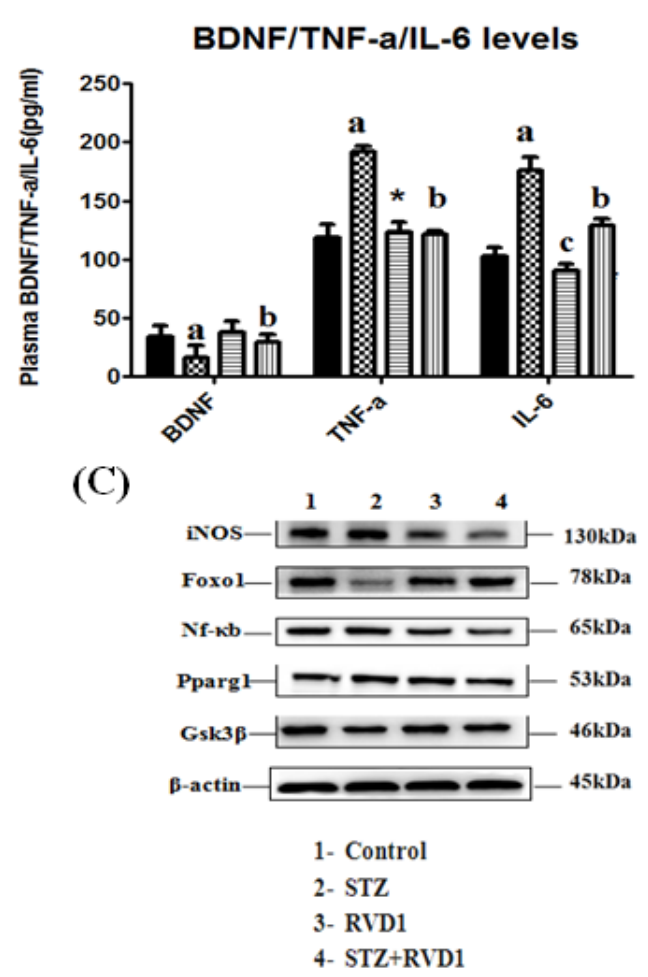

(B)

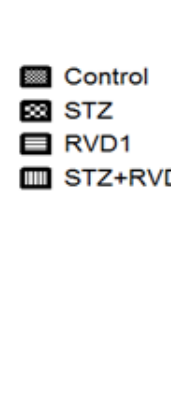

(D)
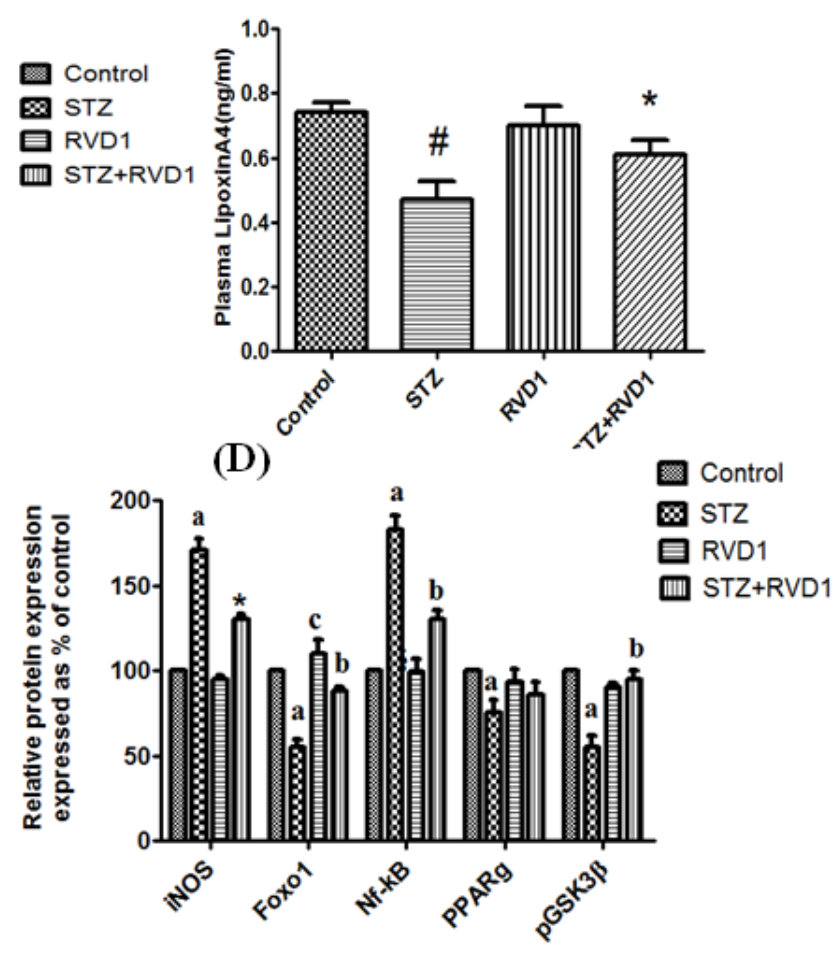

Figure 4. Effect of RVD1 treatment on plasma levels of BDNF/TNF- $\alpha /$ IL-6/LXA4 and protein expression in pancreatic tissue samples. (A) Plasma BDNF/TNF- $\alpha$ /IL-6 levels in STZ + RVD1- vs. STZ (T1DM)-treated groups estimated at the end of the study (day 30). ${ }^{\mathrm{b}} p \leq 0.01$ compared to STZ (T1DM), and ${ }^{\mathrm{a}} p \leq 0.01$ compared to untreated control; TNF- $\alpha$ studies: a $p \leq 0.001{ }^{*} p \leq 0.01$ compared to control and compared to STZ control; and ${ }^{\mathrm{b}} p \leq 0.05$ compared to STZ (T1DM); IL-6 studies: ${ }^{\mathrm{a}} p \leq 0.01$ and ${ }^{\mathrm{c}} p \leq 0.05$ compared to untreated control and STZ control values. ${ }^{\mathrm{b}} p \leq 0.01$ compared to STZ (T1DM) group. All values are expressed as mean \pm SEM. (B) Measurement of LXA4 levels in the plasma of various groups measured at the end of the study (day 30). \# $p \leq 0.001$ compared to untreated control. ${ }^{*} p \leq 0.01$ compared to STZ (T1DM) control (positive control group). (C,D) Protein expression studies in pancreatic tissue of the rats of various groups. Total 
protein extracted from the pancreatic tissue samples were collected at the end of the study (day 30) and used for Western blots for Nf-kb, Foxo1, PPAR- $\gamma, p$-GSK3 $\beta$, iNOS, and beta Actin. Equality of loading of the samples was confirmed by beta actin protein expression. All values are expressed as mean \pm SEM. ${ }^{a} p \leq 0.01$ and ${ }^{\mathrm{c}} p \leq 0.05$ compared to control values. ${ }^{\mathrm{b}} p \leq 0.01$ compared to STZ (T1DM) (these data are taken from Reference [15]). It is evident from this data that resolvin D1 not only prevents STZ-induced type 1 DM in experimental animals but also suppresses inflammation, as evidenced by decreased plasma IL-6 and TNF- $\alpha$ levels and decreased expression of NF-kB and iNOS, and an increase in the circulating levels of LXA4 that was suppressed by STZ treatment. Thus, at least, in part, the anti-inflammatory actions of resolvin D1 are mediated by increased formation of LXA4.

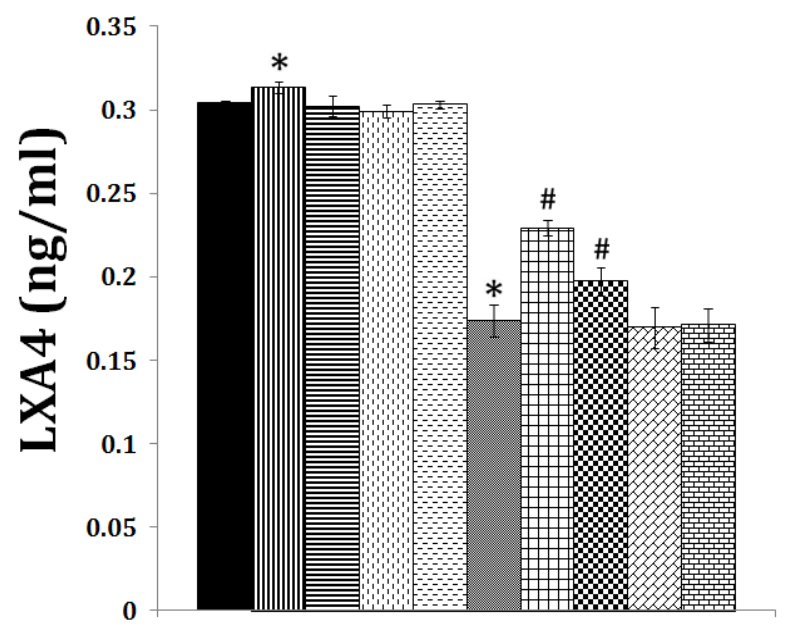

\author{
a Control \\ m $10 \mu \mathrm{g} / \mathrm{ml}$ AA \\ 目 $10 \mu \mathrm{g} / \mathrm{ml} \mathrm{GLA}$ \\ 田 $10 \mu \mathrm{g} / \mathrm{ml} \mathrm{EPA}$ \\ 曰 $10 \mu \mathrm{g} / \mathrm{ml}$ DHA \\ $\square 6 \mathrm{mM}$ ALX \\ $\boxplus 10 \mu \mathrm{g} / \mathrm{ml} \mathrm{AA}+6 \mathrm{mM}$ ALX \\ $₫ 10 \mu \mathrm{g} / \mathrm{ml} \mathrm{GLA}+6 \mathrm{mM}$ ALX \\ 团 $10 \mu \mathrm{g} / \mathrm{ml} \mathrm{EPA+6mM} \mathrm{ALX}$ \\ 国 $10 \mu \mathrm{g} / \mathrm{ml} \mathrm{DHA+6mM} \mathrm{ALX}$
}

(A)

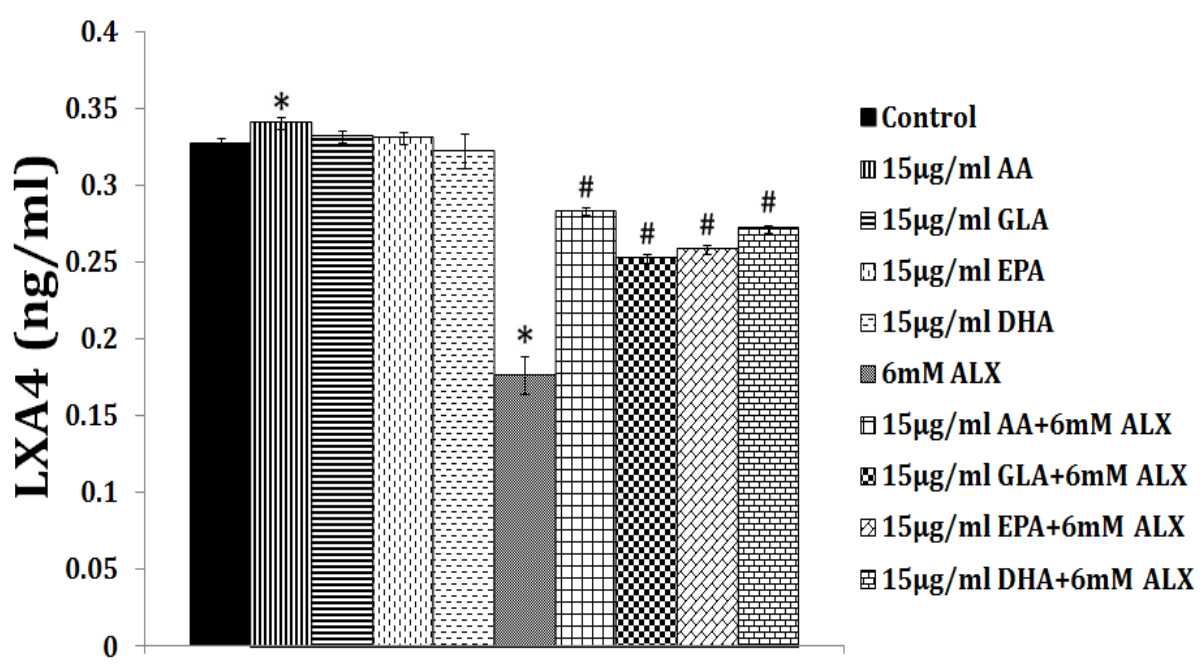

(B)

Figure 5. Effect of alloxan on LXA4 secretion by RIN cells and its modulation by various PUFAs in vitro. ALX = Alloxan. (A) RIN5F (rat insulinoma) cells were treated with $10 \mu \mathrm{g} / \mathrm{mL}$ PUFAs \pm ALX $(6 \mathrm{mM})$ for $1 \mathrm{~h}$. The LXA4 was estimated in the supernatant of the cell cultures. All the above sets of experiments were done in triplicate on two separate occasions $(n=6)$ and values are expressed as mean \pm SEM. ${ }^{*} p \leq 0.05$ compared to untreated control, $\# p \leq 0.05$ compared to ALX. (B) RIN5F cells were treated with $15 \mu \mathrm{g} / \mathrm{mL}$ of PUFAs \pm ALX $(6 \mathrm{mM})$ for $1 \mathrm{~h}$. The LXA4 was estimated in the supernatants of the cell cultures. All the above sets of experiments were done in triplicate on two separate occasions $(n=6)$ and values are expressed as mean \pm SEM. ${ }^{*} p \leq 0.05$ compared to untreated control, \# $p \leq 0.05$ compared to alloxan (ALX). It is seen that at a $10-\mu \mathrm{g} / \mathrm{mL}$ dose of EPA and DHA 
treatment there was no increase in LXA4 secretion by RIN5F cells in vitro in the presence of ALX (6 mM) (A). However, when RIN5F cells were supplemented with $15 \mu \mathrm{g} / \mathrm{mL}$ of EPA and DHA, there was a significant increase LXA4 secretion, even in the presence of ALX $(6 \mathrm{mM})$. These data are taken from [13].

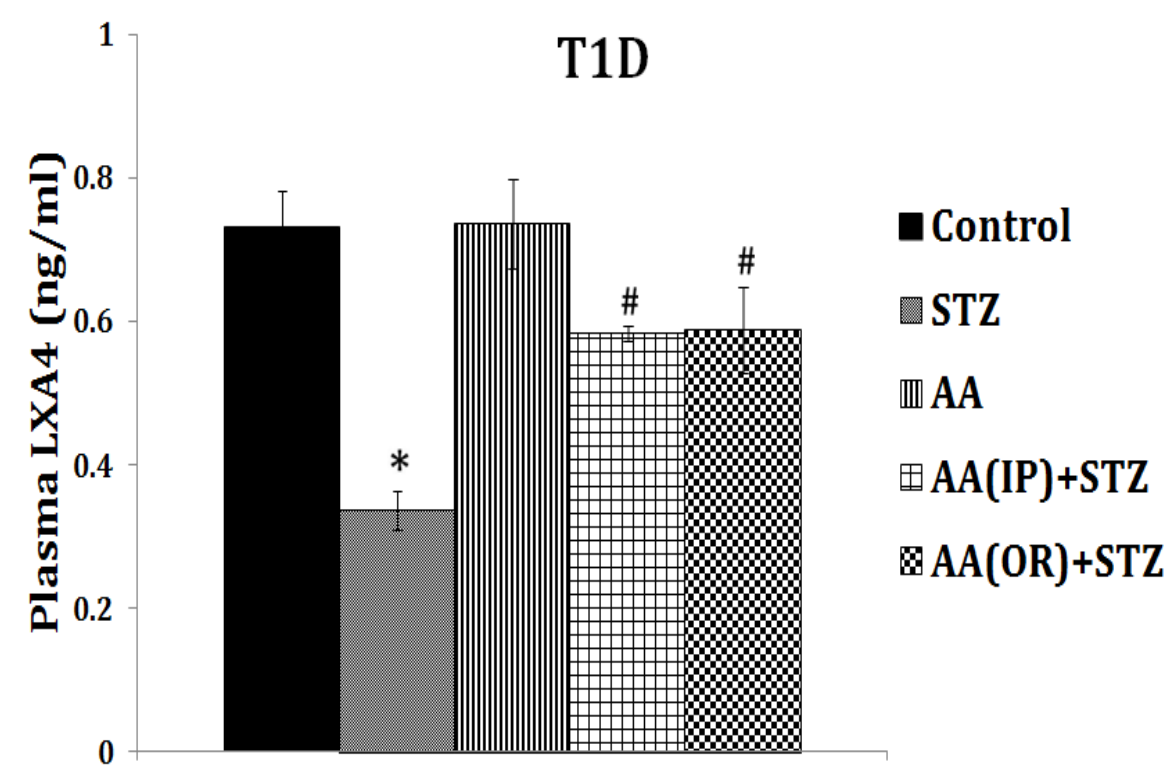

(A)

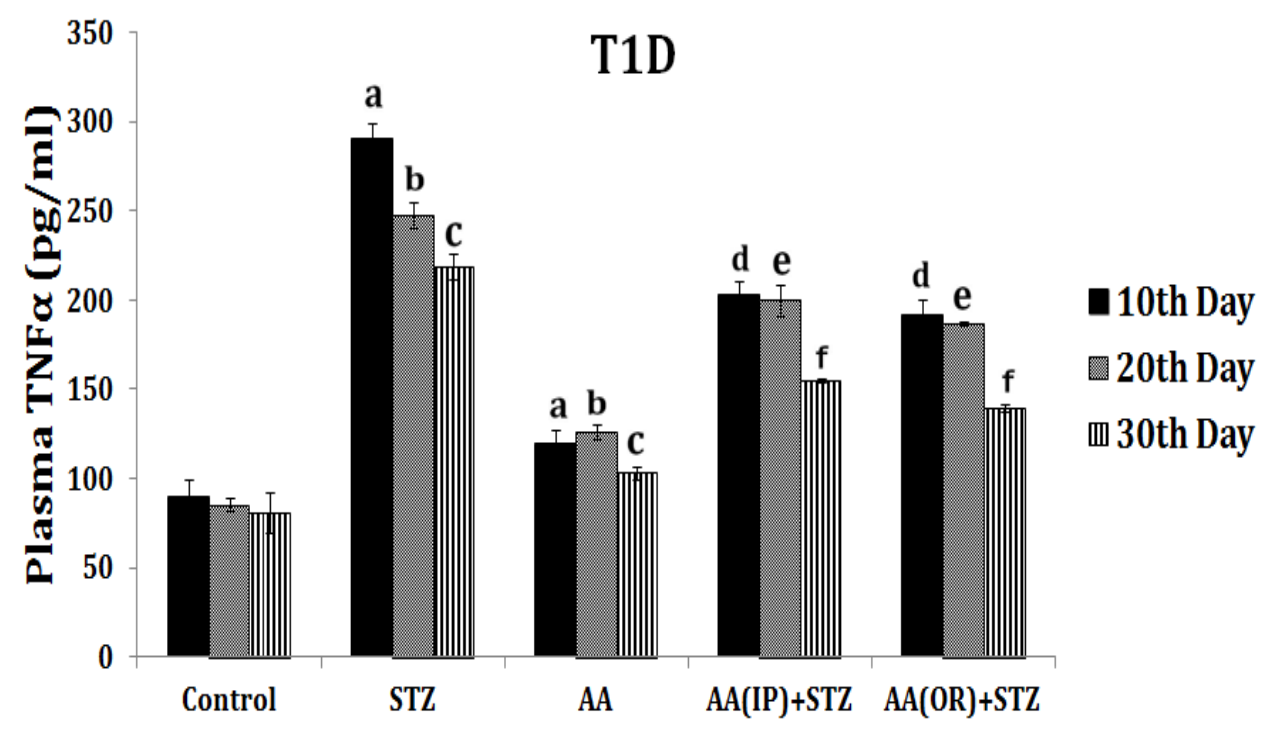

(B)

Figure 6. Effect of arachidonic acid (AA), the precursor of LXA4 and PGE2, on STZ-induced type 1 diabetes mellitus in Wistar rats. Both oral and intraperitoneal (i.p.) administrations of AA (10 $\mu \mathrm{g} / \mathrm{animal}$ for 7 days) not only prevented STZ-induced type 1 diabetes mellitus and restored plasma glucose and insulin to normal but also enhanced plasma LXA4 levels to near control values (A) and suppressed TNF- $\alpha$ levels (B). These results suggest that AA is as potent as LXA4 in preventing diabetes and suppressing inflammation at least, in part, by enhancing LXA4 formation. Thus, AA is a potent anti-inflammatory molecule similar to LXA4. These data are taken from ref. [17]. Similar results were obtained with AA and LXA4 in a STZ-induced type 2 diabetes mellitus animal model (see reference [13]). (A) Measurement of LXA4 levels in plasma of $\mathrm{AA} \pm$ STZ-treated animals at the end of the study (day 30). (B) Plasma TNF- $\alpha$ level in AA \pm STZ treated rats. TNF- $\alpha$ measurement was done in plasma collected once every 10 days until the end of the study. All values are expressed as mean \pm SEM. ${ }^{\mathrm{a}} p \leq 0.05$ compared to the 10 th day of control. ${ }^{\mathrm{b}} p \leq 0.05$ compared to the 20 th day of control. ${ }^{\mathrm{c}} p \leq 0.05$ 
compared to the 30th day of control. ${ }^{\mathrm{d}} p \leq 0.05$ compared to the 10 th day of STZ control. ${ }^{\mathrm{e}} p \leq 0.05$ compared to the 20th day of STZ control. ${ }^{\mathrm{f}} p \leq 0.05$ compared to the 30th day of STZ control. ${ }^{*} p \leq 0.05$ compared to untreated control. $\# p \leq 0.05$ compared to STZ control. All the above studies were done wherein each group consisted of $n=6$ and all values are expressed as mean \pm SEM.

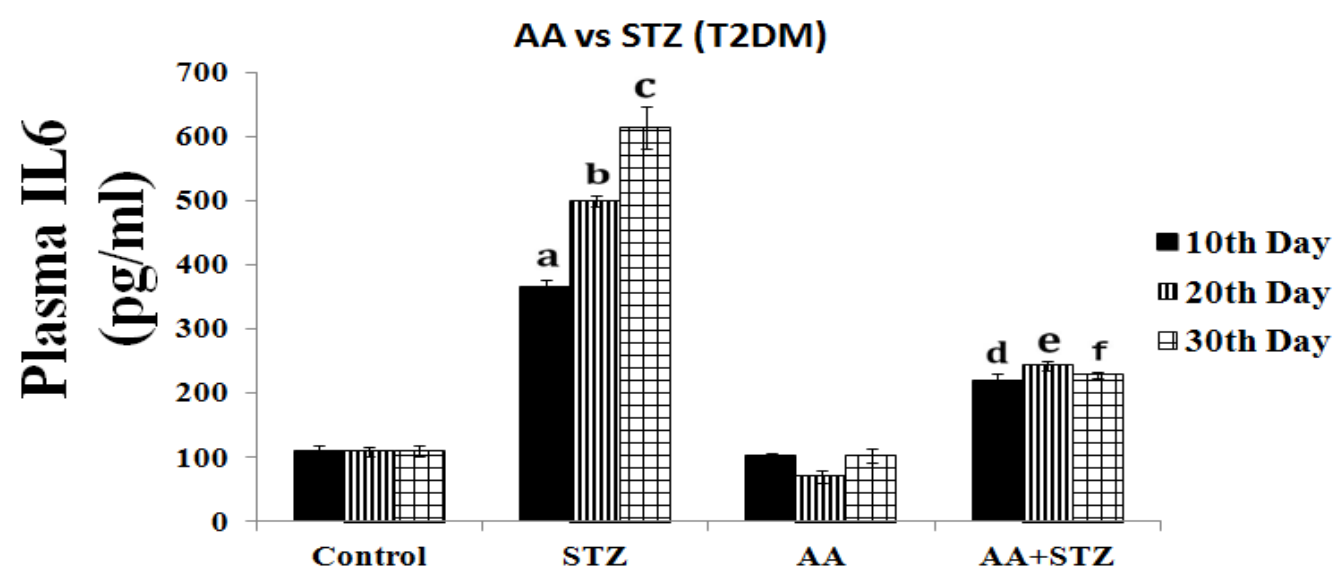

(A)

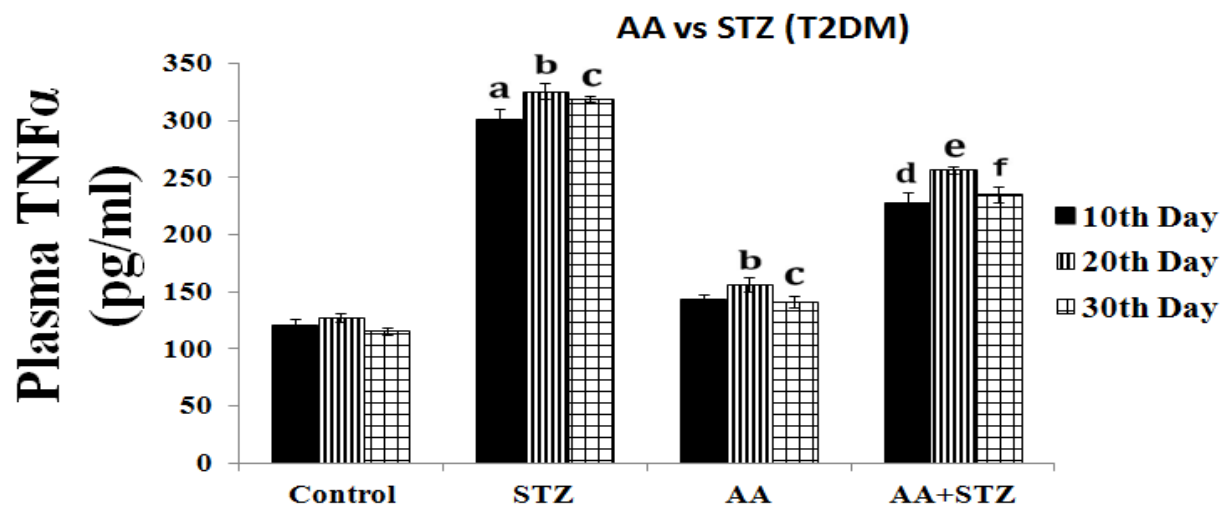

(B)

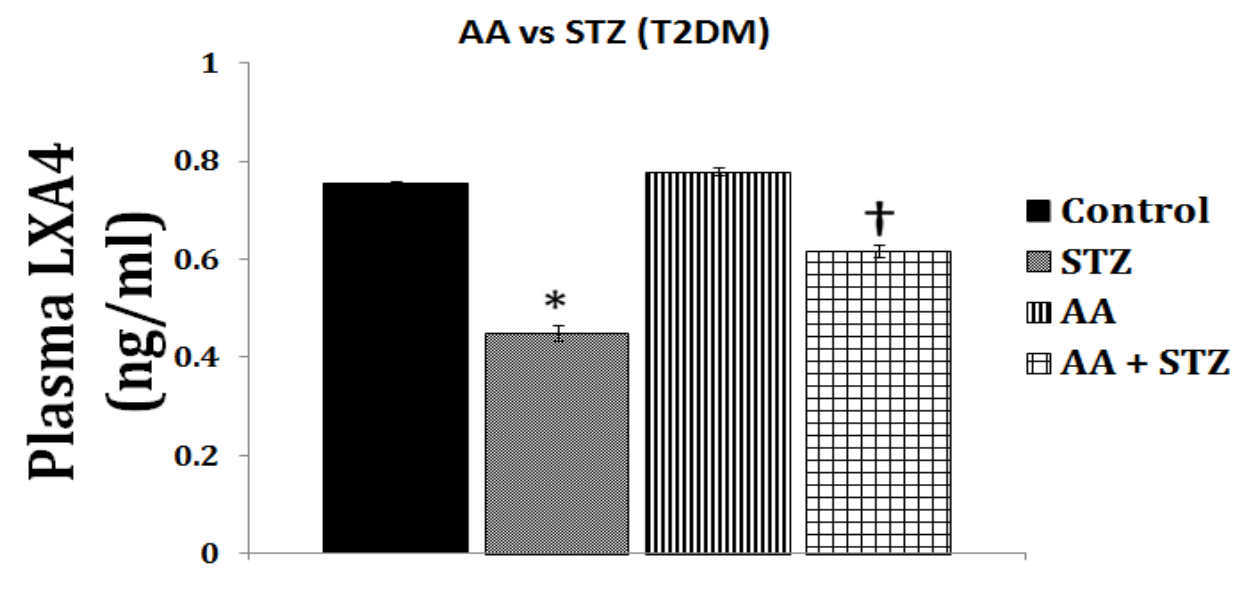

(C)

Figure 7. Cont. 


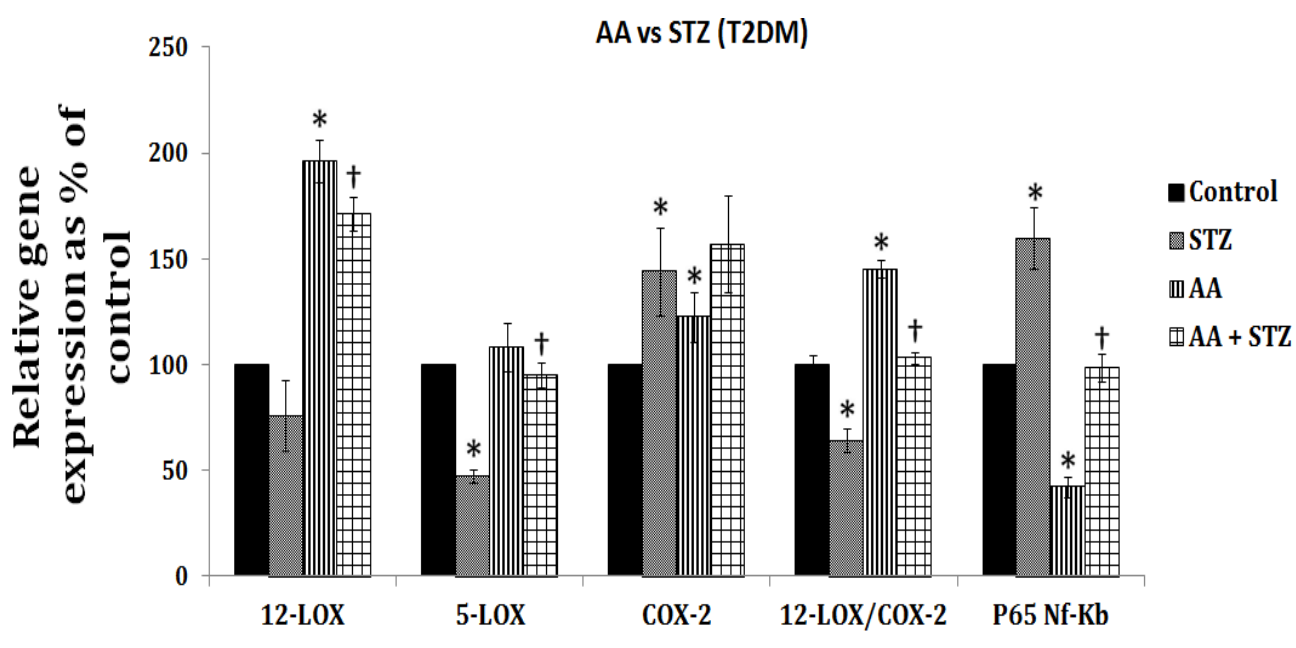

(D)

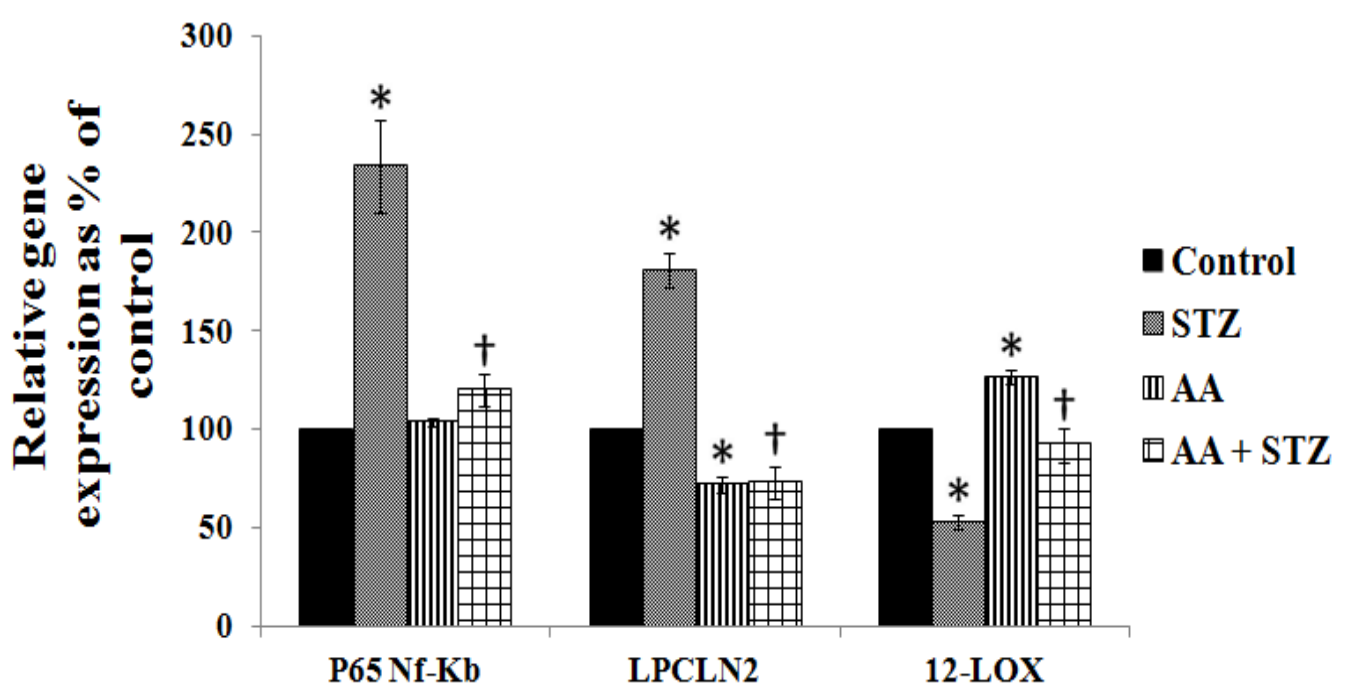

(E)

Figure 7. Effect of AA (orally $10 \mu \mathrm{g}$ /animal for 1 week) on STZ-induced type 2 diabetes mellitus, plasma IL-6 and TNF levels, and expression of pro-inflammatory genes in Wistar rats. AA not only prevented the development of diabetes mellitus but also suppressed plasma IL-6 and TNF- $\alpha$ levels (A,B) and showed enhanced plasma LXA4 levels (C) and the expression of pro-inflammatory NF-KB (in the pancreas) (D) and LPCLN (lipocalin-2) genes in the adipose tissue (E) and restoration to normal the expression of 5-LOX (in the pancreas) (D) and NF- $\kappa \mathrm{B}$ (adipose tissue, (E) genes. Increase in the expression of COX-2 and 12-LOX genes is not surprising since these are needed for the formation of LXA4 from AA. These data are taken from ref. [17]. A. Plasma IL-6 was measured in all animals using a Rat IL-6 ELISA Kit by Abcam (ab100772) Cambridge, USA. IL-6 measurement was done in plasma collected once every 10 days until the end of the study. B. Plasma TNF- $\alpha$ was measured in all animals. Quantikine TNF- $\alpha$ Immunoassay ELISA kit (R \& D Systems, Minneapolis, MN, USA). TNF- $\alpha$ measurement was done in plasma collected once every 10 days until the end of the study. All Values in (A,B) are expressed as mean \pm SEM. ${ }^{\mathrm{a}} p \leq 0.05$ compared to the 10 th day of control; ${ }^{\mathrm{b}} p \leq 0.05$ compared to the 20th day of control; ${ }^{\mathrm{c}} p \leq 0.05$ compared to the 30 th day of control; ${ }^{\mathrm{d}} p \leq 0.05$ compared to the 10 th day of STZ control; ${ }^{\mathrm{e}} p \leq 0.05$ compared to the 20th day of STZ control; ${ }^{\mathrm{f}} p \leq 0.05$ compared to the 30th day of STZ control. C. Measurement of LXA4 levels in plasma of all the groups of animals was performed at the end of the study (day 30). All the values are expressed as mean \pm SEM. ${ }^{*} p \leq 0.05$ compared to untreated control, $+p \leq 0.05$ compared to STZ. (D,E). Gene expression studies in pancreas and adipose tissues. Gene expression studies were performed in the pancreas (D) and adipose (E) tissues collected at end of the experiment. In pancreas, the percentage of change in the expression of genes: 5-LOX, 12-LOX, COX-2, and Nf-kB were studied using the semi-quantitative polymerized chain reaction (PCR) method. The equality of sample loading was confirmed by beta actin gene expression. Quantification of genes was done by Major Science image analysis software. 
In adipose tissue, the percentage of change in the expression of genes 12-LOX, LPCLN2, and Nf-kB was studied using the semi-quantitative polymerized chain reaction (PCR) method. The equality of sample loading was confirmed by beta actin gene expression. Quantification of genes was done by Major Science image analysis software. All the values are expressed as mean \pm SEM. ${ }^{*} p \leq 0.05$ compared to untreated control, $\uparrow p \leq 0.05$ compared to STZ.

This concept is further supported by the known inverse relationship between EFAs and their metabolites in adipose tissue, especially LA, DGLA, AA, and EPA, and mortality due to CHD [18-23]. These results imply that increased consumption of LA and EPA can prevent CHD that could be attributed to increased formation of PGE1 from DGLA (derived from LA) and PGI3 (derived from EPA), both of which are vasodilators and platelet anti-aggregators [24,25]. Studies showed that infusion of DGLA strongly stimulates the release of PGI3 from EPA, a potent vasodilator and platelet anti-aggregator, possibly, via the formation of a hydroperoxide derivative of DGLA [25]. These results suggest that the presence of adequate amounts of both n- 6 and n-3 fatty acids is needed to derive their beneficial actions.

\section{EFAs and Their Metabolites in Inflammation}

GLA, DGLA, AA, EPA, and DHA are potent inhibitors of IL-6 and TNF- $\alpha$ [8-12,26-32]. PGE2 has both pro- and anti-inflammatory actions. Adequate formation of PGE2 is needed to produce an optimal degree of inflammation to occur that, in turn, activates the ALOX12/15 enzyme by 2- to 2.5-fold to enhance the production of anti-inflammatory LXA4 formation [33-36]. The activity of the 12/15 ALOX enzyme was boosted during the initiation of the inflammatory phase, returned to a basal level during the inflamed phase, and then surged again on entering the resolution phase of the inflammatory phase that corresponded to the changes in LXA4 levels: no excess LXA4 production during the peak of inflammation but increased as pathogenesis progressed into the resolution phase. Almost 2-fold higher amounts of LXA4 were formed compared to the basal level during the resolution of the inflammation phase. It is surprising that COX-2 inhibition suppressed LXA4 formation, resulting in continuation or perpetuation of inflammation, indicating that COX-2 influences the synthesis of LXA4 (Figure 7) [33-36]. Similar results have been reported in other inflammatory conditions such as the murine model of autoimmune arthritis [35], intestinal ischemia reperfusion injury [37,38], and in a human skin model of UV-killed Escherichia coli-driven acute inflammation [39] (see Figures 8-11). The results of these studies suggest that PGE2 (and LTB4) need to be high enough to trigger optimum inflammation that, in turn, triggers the synthesis and release of LXA4 (and possibly resolvins, protectins, and maresins) to initiate and induce the resolution of inflammation [33-38,40]. Thus, PGE2 (and LTB4) is critical both to induce inflammation and its resolution. The ability of PGE2 to trigger anti-inflammatory events is further supported by the reports that PGE2, through its receptor EP4, is downregulated in systemic inflammatory conditions such as sepsis [39]. It was found that experimental animals with reduced PGE2 synthesis develop systemic inflammation that is associated with translocation of gut microbiota that could be prevented by EP4 agonists. PGE2-EP4 signals type 3 innate lymphoid cells to produce IL-22 that is needed to inhibit systemic inflammation [39]. These results are supported by the observation that neutrophilic inflammation does not resolve if macrophage-dependent PGE2, which is essential for neutrophil inflammation resolution, is missing. PGE2 seems to signal through the EP4 receptor to augment LXA4 production to induce resolution of inflammation [34]. The ability of PGE2 to enhance LXA4 generation to induce resolution of inflammation is evident from the observation that murine foot pads show increased formation of LXA4 when treated with different concentrations of PGE2 (see Figure 11) [35]. It is noteworthy that even PGE1 enhances LXA4 formation but is much less potent compared to PGE2. These results imply that the anti-inflammatory actions of PGE1 could be due to its ability to enhance LXA4 formation. Similarly, even resolvins D1 (formed from DHA) and E1 (formed from EPA) augment LXA4 formation (see Figures 2-4). These results suggest that, at least to some extent, the anti-inflammatory actions of resolvins 
are brought about by its ability to increase LXA4 formation. As already discussed above, other fatty acids such as GLA, EPA, and DHA have also been shown to increase LX4 formation (see Figure 5), which has been attributed to their (GLA, EPA and DHA) ability to displace AA from the cell membrane phospholipid pool that, in turn, is converted to LXA4. These results suggest that several lipids (such as GLA, EPA, DHA, and resolvins D1, E1, PGE1, and PGE2) are all capable of enhancing LXA4 formation that may underlie the anti-inflammatory action of these compounds. Hence, it is opined that LXA4 is the common mediator of the anti-inflammatory actions of GLA, AA, EPA, DHA, PGE1, PGE2, and resolvins (and, possibly, protectins and maresins). In other words, the ability of a compound to enhance LXA4 formation may determine its degree of anti-inflammatory action: the higher the capacity of a compound to trigger the formation of LXA4, the higher its ability to produce anti-inflammatory action (LXA4 $>$ resolvins $\geq$ protectins $\geq$ maresins $>$ DHA > EPA > GLA $\geq$ PGE1).

The importance of PGE2 is further illustrated from the observation that it is needed for tissue regeneration. For instance, inhibition of 15-PGDH (15-prostaglandin dehydrogenase, a prostaglandin-degrading enzyme) not only produced a 2-fold increase in PGE2 concentrations in the bone marrow, colon, and liver, but also enhanced hematopoietic capacity. The 15-PGDH-deficient animals showed a rapid liver regeneration after partial hepatectomy and enhanced recovery of neutrophils, platelets, and erythrocytes [41]. This is supported by other studies, which showed that PGE2 is needed to promote hematopoiesis and restore hemostasis [42-46]. These results imply that, perhaps, administration of AA, the precursor of both PGE2 and LXA4, may lead to the formation of LXA4 to induce inflammation resolution and PGE2 to trigger tissue regeneration at an appropriate time to augment tissue regeneration.
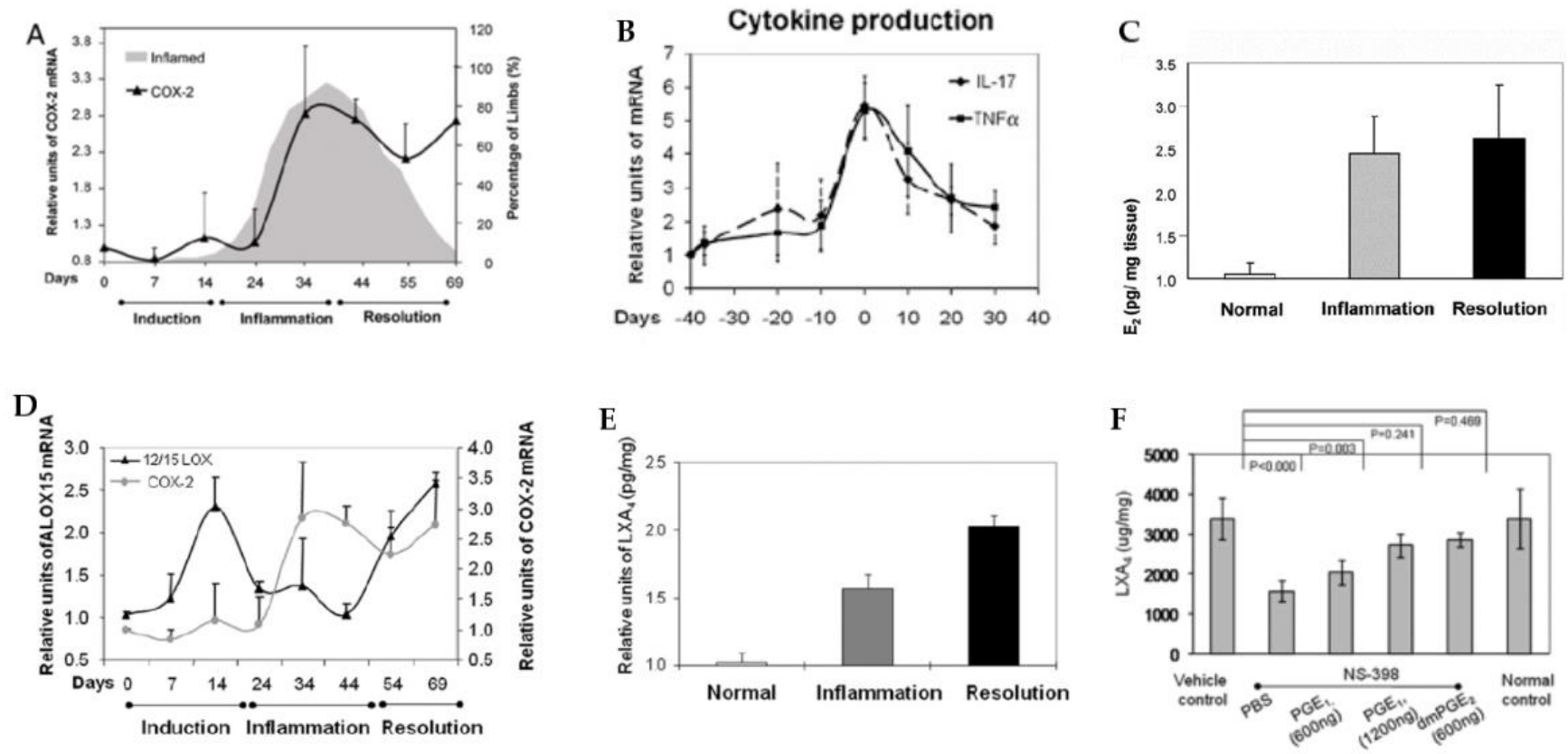

Figure 8. Changes in the expression of COX-2 and cytokines (IL-17 and TNF- $\alpha$ ) in a murine model of autoimmune arthritis. (A,B) PGE2 levels, (C) expression of LOX-15, (D) changes in the concentration of LXA4, and (E) effect of various concentrations of PGE2 on LXA4 production (F) in the joints of murine autoimmune arthritis model (see reference [36]). These data were taken from reference [36] and modified. It is evident from this data that, during the acute inflammation stage, there is enhanced expression of COX-2, increased production of IL-17 and TNF- $\alpha$, augmentation in the production of PGE2, and relatively less production of LXA4 and 12-15-LOX expression. During the phase of resolution of inflammation, the expression of COX-2 (A) and PGE2 (C) production remains high, whereas 12-15-LOX expression is decreased (D) and LXA4 production is elevated (E) with concomitant decrease in IL-17 and TNF- $\alpha$ production (B) that results in resolution of joint inflammation. Both PGE1 and PGE2 enhanced the production of LXA4 (PGE2 > PGE1) (F) by enhancing the expression of ALX, the receptor of LXA4. 
A

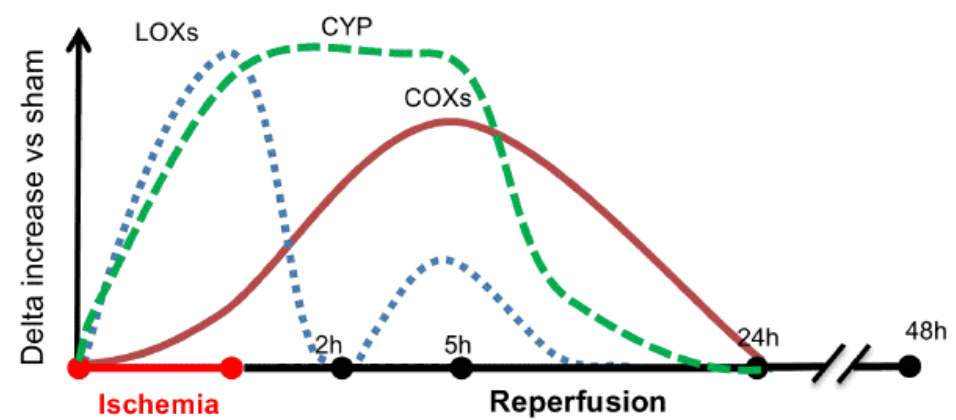

B

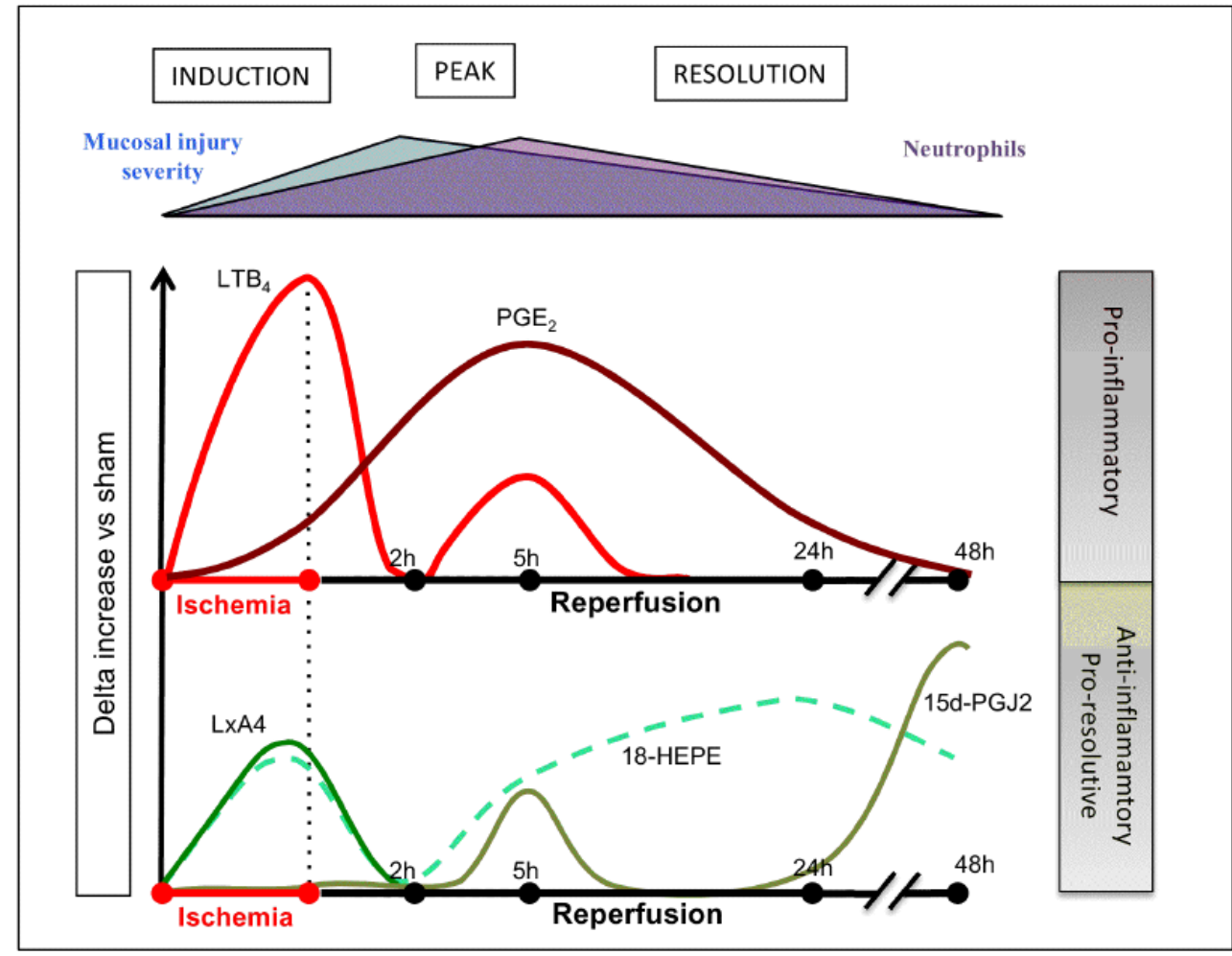

Figure 9. Changes in the concentrations of various bioactive lipids (specifically products of AA, EPA, and DHA) in ischemia reperfusion injury in mouse intestine. These results are somewhat like those seen in Figure 7 except for the fact that, in this study, LTB4 and cytochrome metabolites of AA/EPA/DHA were also measured. It is possible that different tissues may respond differently to injury but the balance between pro- and anti-inflammatory eicosanoids is somewhat similar. It is noteworthy that PGE2 levels (in conjunction with COXs' expression) were gradually enhanced from ischemia to reperfusion phase until healing occurs. LXA4 and LTB4 concentrations were elevated during ischemia (up to $2 \mathrm{~h}$ ) and peaking at $5 \mathrm{~h}$, coinciding with PGE2 levels. These data were taken from ref. [37]. (A) Changes in the activities of COX, LOX and CYP enzymes during ischemia and reperfusion injury. (B) Changes in the concentrations of LTB4, PGE2, LXA4, 18-HEPE and PGJ2 during ischemia and reperfusion injury/inflammation. Notice the relationship between LTB4 and LXA4 (LTB4 > LXA4 and PGE2 > LXA4) during ischemia and reperfusion injury. It may be noted that LTB4 and PGE2 levels are high that. In turn, trigger the production of LXA4 and 18-HETE and PGJ2 that finally induce resolution of inflammation, tissue regeneration and restoration of homeostasis. 

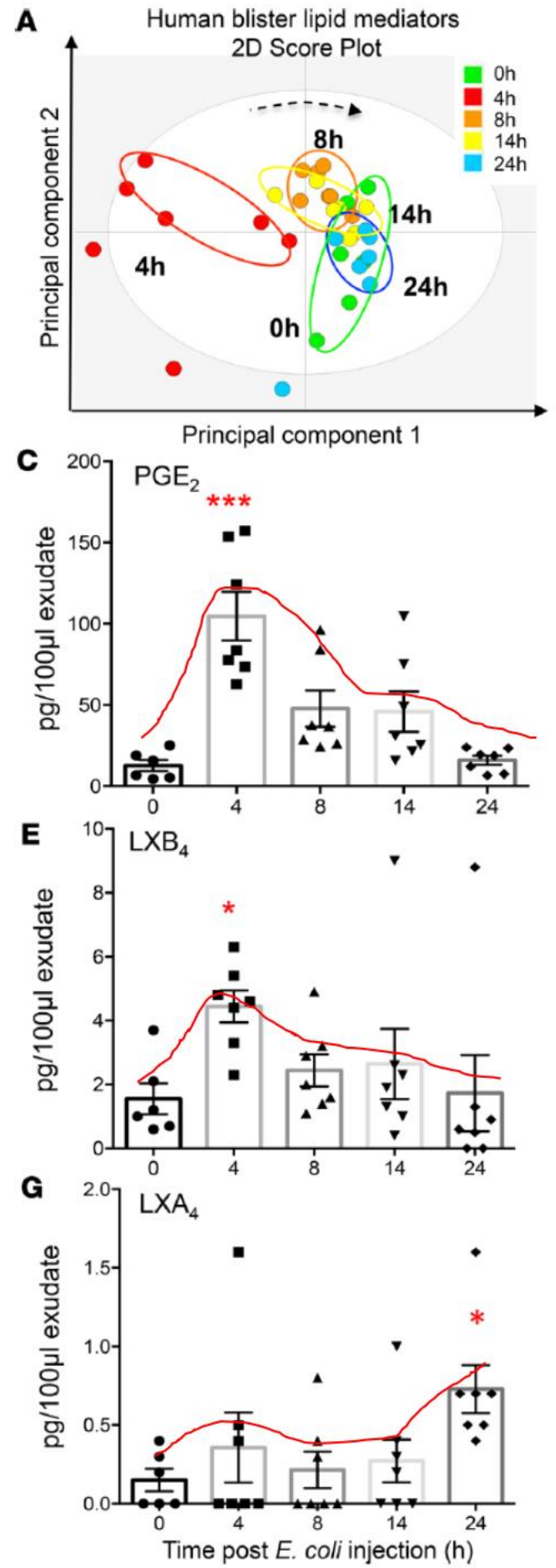
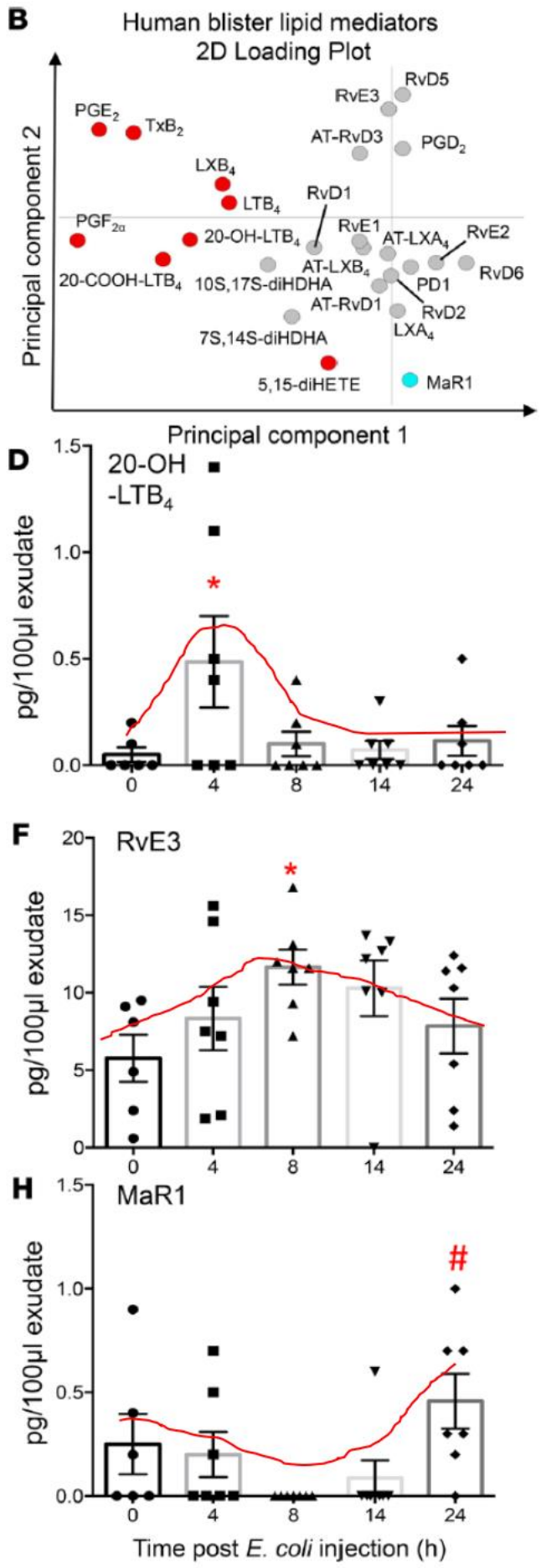

Figure 10. Concentration of both pro- and anti-inflammatory eicosanoids in a human skin model of UV-killed Escherichia coli-driven acute inflammation. It is evident from this study that concentrations of PGE2 and LTB4 coincide with the peaking of LXB4 and LXA4 and the beginning of a gradual but definite increase in those of resolvin E3. Paradoxically, the increase in maresin was not seen until the end of almost $24 \mathrm{~h}$. The results of this study confirm the importance of PGE2 (and of LTB4) as initiators of resolution of inflammation by triggering the initiation of production of anti-inflammatory LXA4 and LXB4, which is supported by the subsequent generation of resolvin E3 (with a gradual increase and decrease from 4 to $24 \mathrm{~h}$ ), a paradoxical fall in the generation of maresin from 4 to $14 \mathrm{~h}$, and an increase by $24 \mathrm{~h}$. These results also emphasize that there are some specific actions for various eicosanoids in the process of inflammation and its resolution and restoration of homeostasis, though the exact role of each type of eicosanoid needs to be deciphered. These data are from reference [40]. ${ }^{*} p<0.05 ; \# p<0.05, * * * 0.05$ compared to control. 


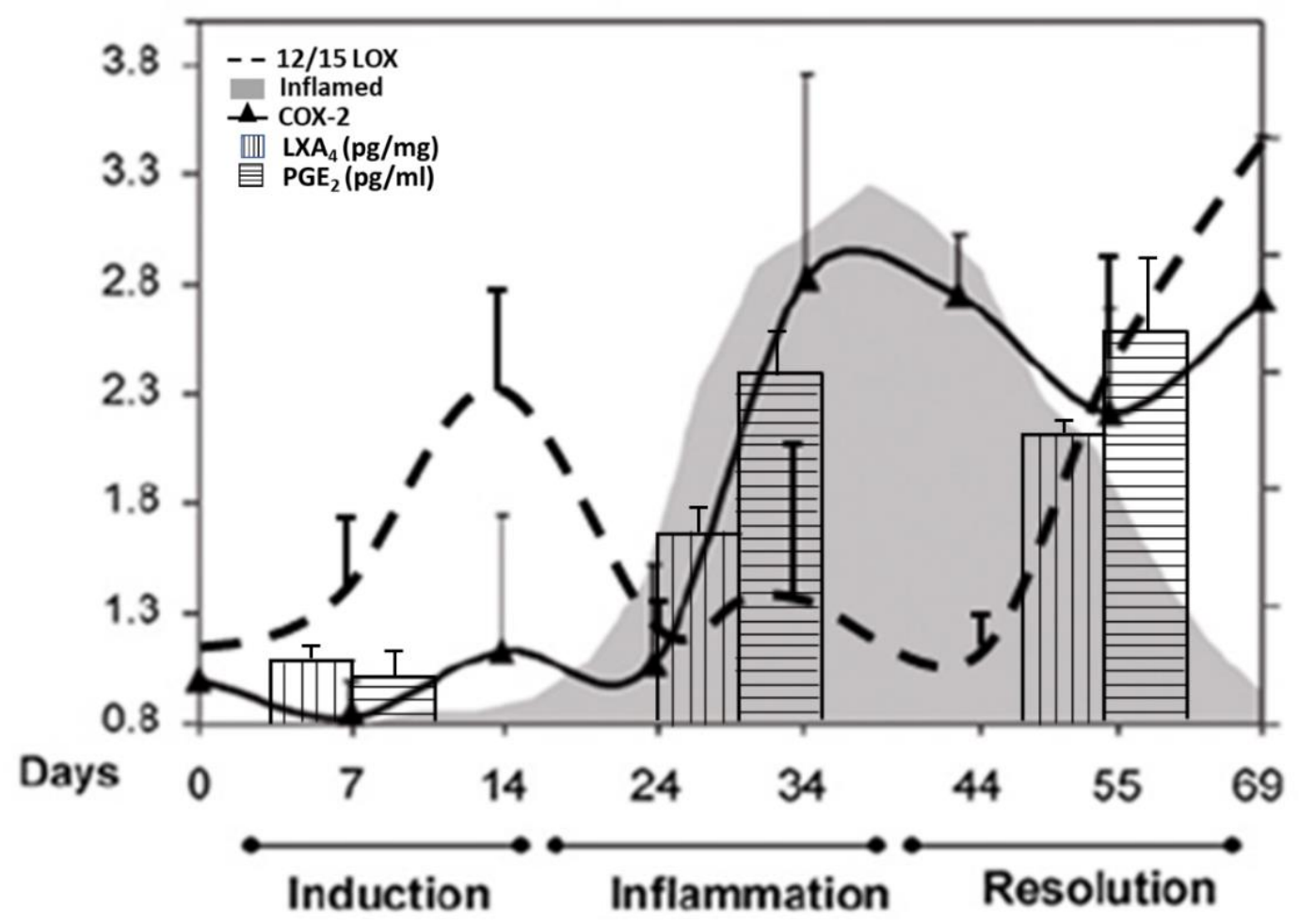

Figure 11. A summary scheme showing potential relationship among COX-2/LOX enzymes and PGE2/LXA4, and induction, active inflammation, and resolution of inflammation based on the data derived from Figures 8-10.

Since both PGE2 and LXA4 are formed from AA, it is likely that AA metabolism is crucial to the inflammatory process and its resolution. Thus, the balance between PGE2 and LXA4 (a similar balance may exist between PGE3/LTE5 and resolvins, protectins, and maresins but has not been studied so far) and the tissue concentrations of GLA, DGLA, AA, EPA, and DHA (as modulators of IL- 6 and TNF- $\alpha$ production and action) is crucial to determine the final status of the inflammatory events. GLA, DGLA, AA, EPA, and DHA are not only important constituents of the cell membrane but also modulate its fluidity that, in turn, influences the expression of several receptors and their binding properties. PGE2 and LTs facilitate generation of M1 macrophages (which are pro-inflammatory in nature), whereas GLA, DGLA, AA, EPA, DHA, PGE1, LXA4, resolvins, protectins, and maresins favor generation of M2 macrophages [47-54] (which are anti-inflammatory in nature), which may be relevant to the involvement of these bioactive lipids in COVID-19. It is interesting to note that the M1 phenotype is associated with 6-keto PGF1 $\alpha$, PGE2, and LTB4 [54]. Since PGE2 is associated with both M1 and M2 macrophages, it can be argued that, in the early phase of inflammation, when PGE2 concentrations are still peaking, it (PGE2) facilitates M1 generation. In contrast, when PGE2 levels have reached their peak it triggers the inflammation resolution process by stimulating LXA4 formation, and it (PGE2) facilitates M2 generation [48-52,54].

As discussed above, the induction of an adequate degree of inflammation is needed to trigger inflammation resolution events and restoration of homeostasis [33-40]. PGE3 and LTs of 5 series formed from EPA are less pro-inflammatory compared to PGE2 and LTs of 4 series formed from AA [10]. This implies that PGE3 and LTs of 5 series do not trigger inflammation of a sufficient degree to initiate the inflammation resolution process. Hence, it is likely that resolvins, protectins, and maresins derived from EPA and DHA may be inadequate to trigger an efficient inflammation resolution process even though they are potent anti-inflammatory compounds. Previously, we showed that EPA and DHA displace AA from the cell membrane lipid pool to enhance the formation of LXA4 (see Figure 5). But LXA4 formed as a result will be insufficient to induce full remission of the inflammatory process. This is so since the concentrations of LXA4 formed are much lower 
compared to those formed following AA supplementation [13]. It is noteworthy that LXA4 generation is enhanced by resolvin treatment $[14,16]$ (see Figures 2 and 3, and Figures 4-6 for anti-inflammatory actions of AA and LXA4). Based on these results, it is proposed that the formation of adequate amounts of LXA4 is critical for the resolution of inflammation.

Both pre-treatment (exposing the RIN5F cells initially to resolvin/protectin/LXA4 and then to alloxan) and simultaneous treatment (RIN5F cells were exposed to LXA4/resolvin/ protectin and alloxan at the same time) studies showed that LXA4 is the more potent compared to resolvins and protectins in preventing alloxan-induced cytotoxicity to RIN5F (rat insulinoma) cells in vitro [17]. Similarly, LXA4 was more potent compared to resolvins and protectins in preventing the cytotoxic action of benzo(a)pyrene, streptozotocin, and doxorubicin [13-15,17]. In addition, AA showed potent anti-inflammatory action by virtue of its ability to suppress IL- 6 and TNF- $\alpha$ production and the expression of NF- $\mathrm{kB}$ and prevented both alloxan- and streptozotocin-induced type 1 and type 2 diabetes mellitus in experimental animals $[13,17,55]$. This anti-inflammatory action of AA seems to be brought about, at least, in part, by enhancing the formation of LXA4. Thus, PGE2 and LXA4 derived from AA appear to be the most suited to induce inflammation and initiate and resolve inflammation in an optimal fashion (see Figures 7-13).

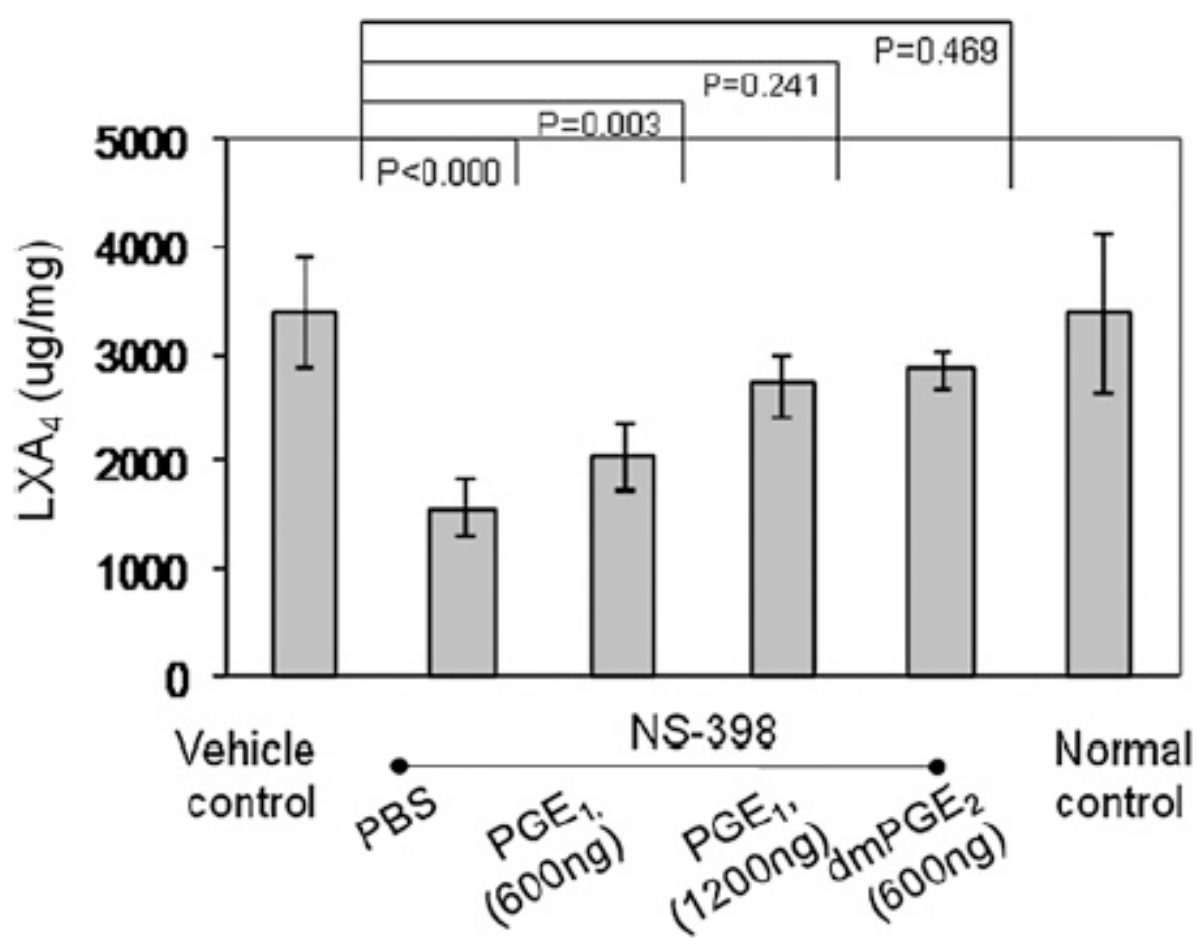

Figure 12. Effect of PGE1 and PGE2 on the generation of LXA4. This study was performed in the foot pads of the murine collagen-induced arthritis. It is evident form this data that PGE1 and PGE2 can enhance LXA4 formation. PGE2 is more potent than PGE1 to induce LXA4 generation when tested at the same concentration. These data are taken from reference [35]. 


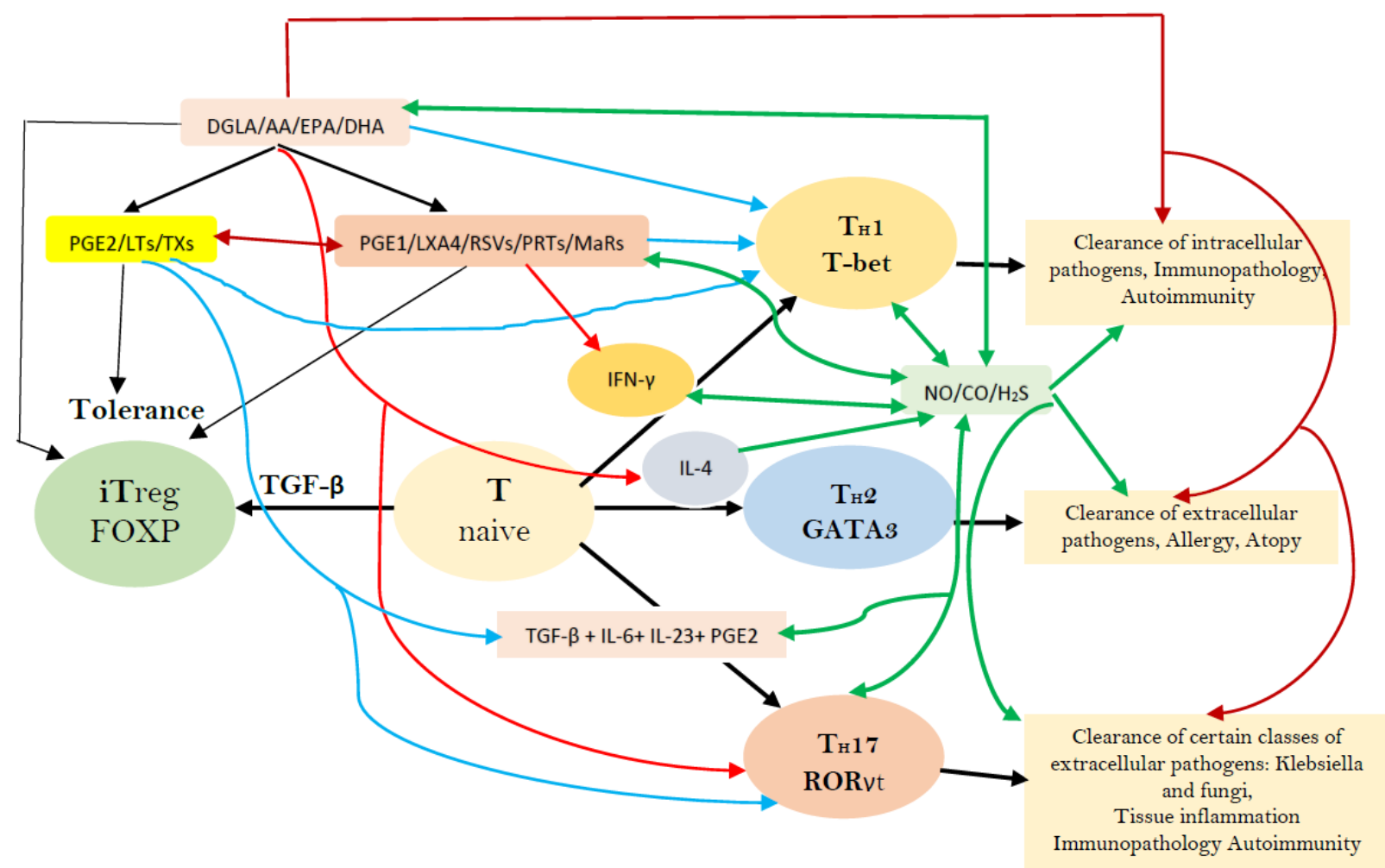

Figure 13. Factors that have a regulatory role in the formation of different subsets of $\mathrm{T}$ helper cells. RSVs = Resolvins; PRTs = Protectins; MaRs = Maresins $;$ LXA4 = Lipoxin A4; LTs = Leukotrienes; TXs = Thromboxanes; NO = Nitric oxide; $\mathrm{CO}=$ Carbon monoxide; $\mathrm{H}_{2} \mathrm{~S}=$ Hydrogen peroxide; TGF- $\beta=$ Transforming growth factor $\beta$; IFN- $\gamma=$ Interferon- $\gamma$. Naive CD41 T cells differentiate into T helper cells: $\mathrm{T}_{\mathrm{H}} 1, \mathrm{~T}_{\mathrm{H}} 2$, and $\mathrm{T}_{\mathrm{H}} 17$. TGF- $\beta$ converts naive T cells into FOXP3-expressing induced Treg (iTreg) cells. T helper cell differentiation needs T-bet, GATA3, and ROR- $\gamma$ t. Terminally differentiated T helper cells produce a specific combination of effector cytokines needed for the adaptive immune system. TGF- $\beta$, retinoic acid, or cytokines: IL-6, IL-1, IL-23, or IL-27 secreted by the innate immune system cells (immature or activated dendritic cells (DCs), respectively) dictate whether a naive $T$ cell develops into a FOXP31 Treg cell, a $\mathrm{T}_{\mathrm{H}} 17$ cell, or otherwise. PGE2 through its receptor EP4 on T cells and dendritic cells facilitates $\mathrm{T}_{\mathrm{H}} 1$ cell differentiation and amplifies IL-23-mediated $\mathrm{T}_{\mathrm{H}} 17$ cell expansion. Bioactive lipids modulate the generation, proliferation, and function of several immunocytes, and their secretion of soluble mediators and nitric oxide (NO)/carbon monoxide (CO)/hydrogen sulfide $\left(\mathrm{H}_{2} \mathrm{~S}\right)$ has a modulatory action on various immunocytes and their actions, as shown in the figure. This figure is taken from reference [56]; for more details, see reference [56].

\section{PGE2 and LXA4 Regulate Inflammation and Its Resolution}

It is believed that AA is harmful, with the impression that its administration enhances PGE2 formation, a pro-inflammatory molecule. It is noteworthy that LXA4, a potent antiinflammatory compound, is also derived from AA [10,16,56-59]. AA can be given orally (840 to $2000 \mathrm{mg}$ /day) for 50 days to healthy individuals with no increases in inflammation or related metabolic activities [60]. AA can be administered intravenously when prepared suitably [61]. AA supplementation to animals and humans enhanced its tissue content with no change in PGE2 levels, but an increase in LXA4 formation was reported [62-64]. My own studies and those of others $[13,17,33,65-68]$ revealed that AA has potent anti-inflammatory action. Like AA, LXA4 prevented the development of alloxan- and streptozotocin-induced type 1 and type 2 diabetes mellitus, respectively, and suppressed IL- 6 and TNF- $\alpha$ production and NF-kB expression.

Paradoxically, PGE2 seems to have an anti-inflammatory action as well. PGE2 suppresses IL- 6 and TNF- $\alpha$ production and alters macrophage polarization induced by mesenchymal stem cells (MSCs) [69-75]. PGE2 binds to both EP2 and EP4 receptors depending on its concentration. At low concentrations, PGE2 binds to EP4, a high affinity receptor, 
and enhances the production of IL-23, whereas high PGE2 amounts bind to EP2 receptor to inhibit IL-23 production [76]. Furthermore, PGE2 triggers the production of LXA4 and inhibits LTB4 synthesis by modulating the expression of 5- and 15-lipoxygenases and, thus, triggers the anti-inflammatory pathway to induce resolution of inflammation $[35,36]$. This interaction and crosstalk among macrophages, neutrophils, PGE2, LXA4, and LTB4 are essential to trigger the much needed inflammation and initiate inflammation resolution. This redirection of the AA metabolism from PGE2/LTB4 to LXA4 seems to depend on the biphasic release of AA from the cell membrane lipid pool. The first phase of AA release in response to iPLA2 (calcium-independent phospholipase A2) activation results in the conversion of AA to PGE2, whereas the second wave of AA release in response to cPLA2 and sPLA2 (cytosolic and soluble phospholipase A2, respectively) activation results in the generation of LXA4. This specific and unique process of utilization of released AA to form either PGE2/LTB4 or LXA4 regulates inflammation and its resolution that is partly dependent and regulated by the local concentrations of IL-1 $\beta$, IL-4, and IL-10 [33].

\section{Critical Role of AA in Inflammation Resolution}

Under normal physiological conditions a delicate balance is maintained between pro-inflammatory $\mathrm{T}_{\mathrm{H}} 1$ (IL-2, IFN- $\gamma$ ) and anti-inflammatory $\mathrm{T}_{\mathrm{H}} 2$ cytokines (IL-4, IL-5, IL-10, IL-13) to regulate inflammation. IFN- $\gamma$-producing CD4+ $\mathrm{T}_{\mathrm{H}} 1$ cells and PGE2 are needed to control invading microbial inflammatory stimuli to initiate and maintain the mononuclear inflammatory response. IL-17 $\left(\mathrm{T}_{\mathrm{H}} 17\right)$, a pro-inflammatory cytokine, formation is dependent upon IL-23 and PGE2, which induces chemokine expression and recruitment of cells (see Figure 14) [33,77-82]. PGE1, LXA4, resolvins, protectins, and maresins, by virtue of their negative feed-back control on the production of PGE2, LTs, and thromboxanes (that have pro-inflammatory actions), inhibit the formation of $\mathrm{T}_{\mathrm{H}} 17$ cells and their production of proinflammatory IL-17, IL-22, and IL-23 in view of the close interaction among these cytokines (IL-17, IL-22, IL-23) [82-86]. Once the purpose of inflammatory response is achieved, IL-10, IL-4, and LXA4 (and, possibly, resolvins, protectins, and maresins) are produced to initiate and induce the resolution of inflammation [33-40]. Thus, PGE2 (LTs and thromboxanes) and LXA4 (and the other anti-inflammatory bioactive lipids, PGE1, resolvins, protectins, and maresins) are needed to initiate and resolve inflammation, respectively.

AA and LXA4 suppress NF- $\mathrm{BB}$ expression that is essential for enhancing the IL-17 and IL-23 production $[10,13,16,17,33,40,87-89]$ that seems to play a major role in COVID19 [90-94]. IL-6, TNF- $\alpha$, and IL-17 enhance iNOS (inducible nitric oxide) expression that, in turn, augments PD-L1 (programmed death-ligand 1) expression in MSCs (mesenchymal stem cells) [95-97]. This renders MSCs to be recognized as self that is essential to facilitate their (MScs') survival, proliferation, and differentiation to restore homeostasis after the inflammation has resolved and all the debris at the site of injury has been removed [98]. However, this action of IL-17 on MSCs and their expression of PDL-1 may also have an unwelcome consequence, namely, failure/suppression of recognition of SARS-CoV-2 and other microbial-infected cells as non-self and mount an immune attack to eliminate them. As a result, the infected cells may survive and aid in the proliferation and spread of infection to other cells/tissues.

Resolvin E1 and E2, derived from EPA, resolvins of D series, and protectins and maresins derived from DHA have anti-inflammatory actions like LXA4 and suppress IL-23 and IL-17 production in addition to their ability to inhibit IL-6 and TNF- $\alpha$ [99-102]. Resolvin E1 promotes LXA4 production, implying that LXA4 is the mediator of the actions of resolvin E1 [14-16] (see Figures 2-4). LXA4 attenuates liver fibrosis by suppressing TNF- $\alpha$, IFN- $\gamma$, IL-2, and IL-17 and augmenting IL-4 and IL-10 production [103], implying that LXA4 and its precursor AA may be of benefit in preventing the lung fibrosis seen in some patients with COVID-19 (termed as long-haulers). This is in addition to the ability of LXA4/AA to suppress acute lung injury [104,105]. In this context, it is noteworthy that the beneficial actions of MSCs and other types of stem cells in the management of SARS-CoV-2 
infection (COVID-19) and other inflammatory conditions could be attributed to their ability to secrete PGE2 and LXA4 as needed [69-72,74,75,106-117].
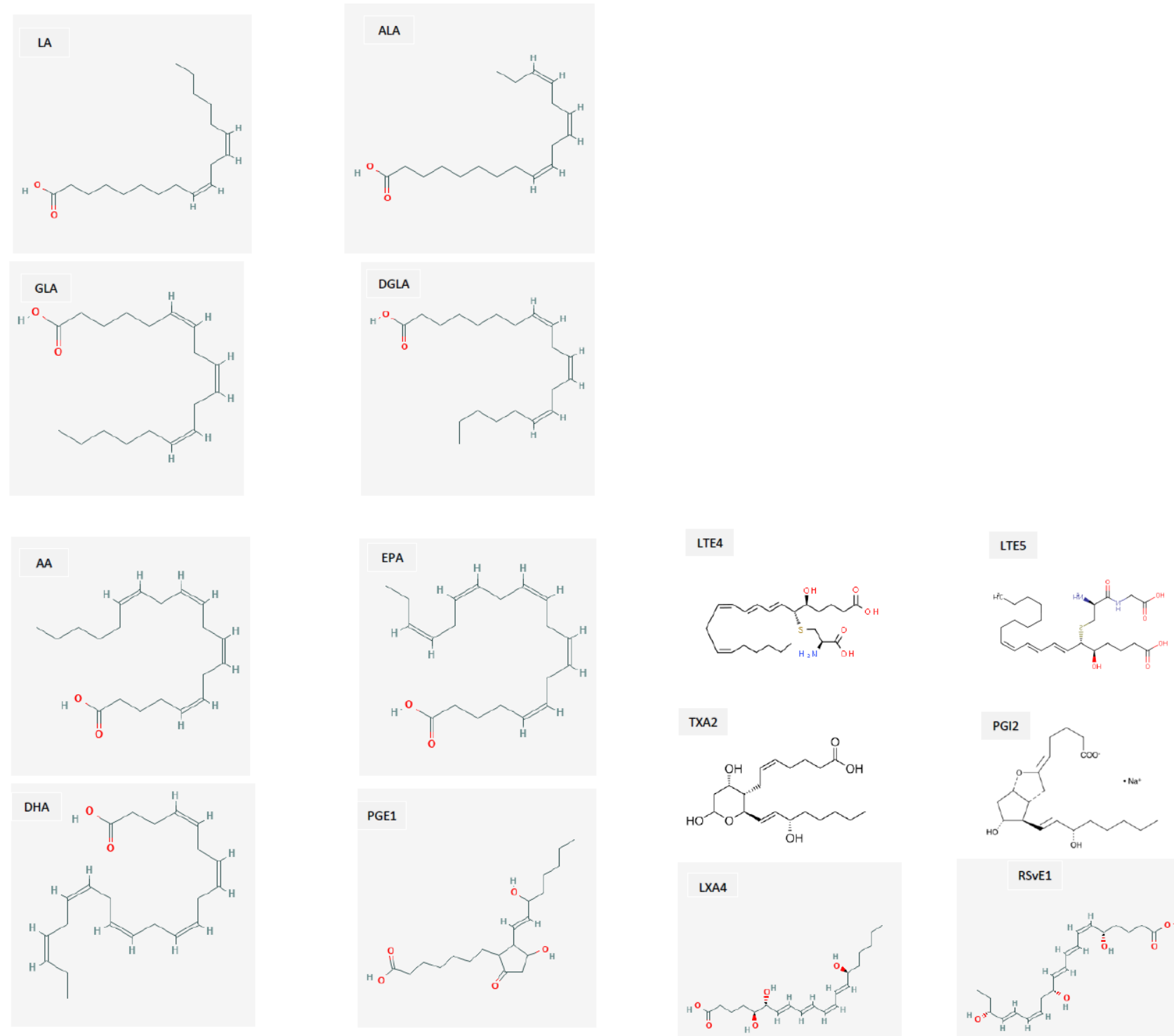

RSvE1

PGE2
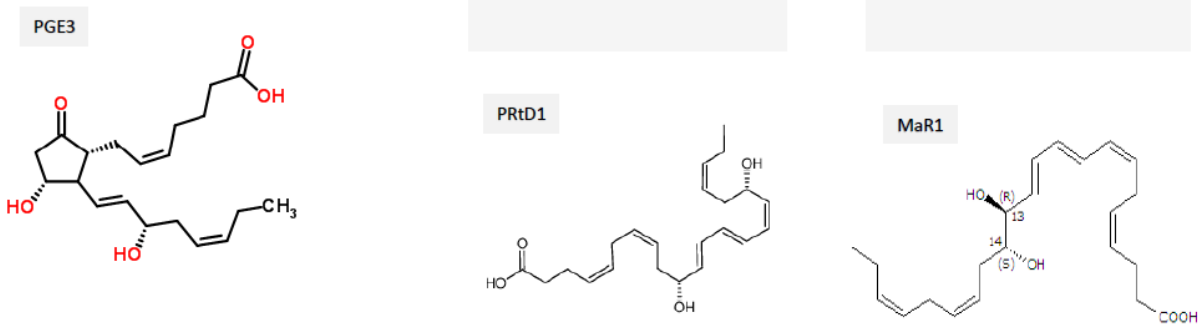

Figure 14. Structures of various BALs. Abbreviations: LA = Linoleic acid; ALA = Alpha-linolenic acid; GLA = Gammalinolenic acid; DGLA = Dihomo-gamma-linolenic acid; $\mathrm{AA}=$ Arachidonic acid; EPA = Eicosapentaenoic acid; DHA = Docosahexaenoic acid; PGE1, PGE2, and PGE3 = Prostaglandin E1, E2, and E3, respectively; TXA2 = Thromboxane A2; LTE4 and LTE5 = Leukotriene E4 and E5, respectively; PGI2 = Prostacyclin; LXA4 = Lipoxin A4; RSvE1 = Resolvin E1; PRtD1 = Protectin D1; Mar1 = Maresin1.

My studies revealed that the inhibitory action of AA and LXA4 on the production of IL- 6 and TNF- $\alpha$ is to the same extent that was exerted by resolvin E1, implying that LXA4 is as potent as resolvin E1 (and resolvin D1, unpublished data) in its anti-inflammatory 
action (see Figures 2-6) [13-15,17]. AA, the precursor of LXA4 and PGE2, prevented streptozotocin (STZ)-induced type 1 and type 2 diabetes mellitus and suppressed plasma IL- 6 and TNF- $\alpha$ levels and the pro-inflammatory gene NF- $\mathrm{KB}$ to the same extent as that of LXA4 (see Figures 6 and 7). AA treatment also restored plasma LXA4 levels to normal by augmenting the expression of COX-2 and 12-LOX genes (see Figures 6 and 7). Since resolvins enhance the production of LXA4 to bring about their anti-inflammatory and cytoprotective actions [14-16] (see Figures 2-4), it is reasonable to suggest that a crosstalk occurs between n-3 and n- 6 fatty acids' metabolism in such a way that LXA4 production is enhanced to resolve inflammation. This implies that plasma and tissue concentrations of AA are critical to achieve optimal inflammation resolution.

EFA metabolism is modulated by several factors including but not limited to folic acid; vitamins B1, B2, B6, and B12; vitamin C; cholesterol; dietary saturated fats; trans fats; ethanol; iron; magnesium; zinc: and drugs such as statins (see Figure 1). Folic acid, B1, B2, B6, B12, and magnesium are co-factors needed for optimal activity of desaturases, whereas vitamin $C$ is needed for the formation of PGE1 from DGLA. Insulin activates desaturases. Saturated (including cholesterol) and trans fats inhibit the activity of desaturases. A deficiency of GLA, DGLA, AA, EPA, and DHA due to low activity of desaturases increases the rigidity of cell membrane, as seen in those with diabetes mellitus, hypertension, and coronary heart disease, who have decreased plasma and tissue concentrations of GLA, DGLA, AA, EPA, and DHA [8-12,18-22]. Hyperglycemia inhibits the activities of desaturases, leading to a decrease in the formation of GLA, DGLA, AA, EPA, and DHA even if the dietary intake of LA and ALA are adequate. This may result in a decreased formation of PGE1 (from DGLA), PGI2, PGJ2, and LXA4 (from AA), resolvins (from EPA and DHA), and protectins and maresins (from DHA) that are needed to suppress inappropriate inflammation.

\section{AA and Other Bioactive Lipids Possess Antimicrobial Action}

Whenever human cells and tissues are invaded by microbes, the host immune system is activated to eliminate or neutralize them by generating specific antibodies, immunocytes elaborate suitable cytokines and reactive oxygen species (ROS), activate complement system, and other specific and non-specific means to trap and kill them. In this process there could occur little or no injury to various tissues, though some amount of inflammation, injury, and cell/tissue damage is inevitable. The elimination of invading microbes and the resolution of inflammation and subsequent repair of the tissue damage must occur in a coordinated and orderly fashion. This can occur only if there is a crosstalk among the invading organisms, the host tissues under attack, and the immune system, as discussed above. In addition, when the microbes invade the cells/tissues, they invariably perturb/disrupt membrane integrity during cell entry, leading to the activation of phospholipase A2 (PLA2) that induces the release of various bioactive lipids (BALs) such as LA, GLA, DGLA, AA, ALA, EPA, and DHA. These lipids have anti-microbial actions and can act intracellularly through one of five membrane $G$ protein-coupled receptors (GPCRs) in immune cells, resulting in diverse effects on innate immune function. Studies revealed that BALs can inactivate or kill Staphylococcus aureus and coagulase-negative staphylococci, group A streptococci, fungi, and enveloped viruses, including influenza and HIV [118-136]. Of all the fatty acids tested, AA seems to be the most potent and crucial in inducing not only the anti-microbial action of macrophages, NK cells, and other immunocytes but also the pathobiology of inflammation and its resolution, as discussed above. AA and other fatty acids seem to induce their antimicrobial action by their ability to induce leakage and even lysis of microbial cell membranes (including disruption of viral protein envelopes), as well as various cellular metabolic effects, including but not limited to inhibition of respiratory activity, effects on transportation of amino acids, and uncoupling of oxidative phosphorylation [133-137]. In addition, Staphylococci in the lung alveoli are killed mainly outside alveolar macrophages that resides in the AA present in the surfactant [119-123]. 
It has been proposed that alveolar macrophages, leukocytes, T and B cells, NK cells, and other immunocytes release AA and other unsaturated fatty acids into their surrounding milieu when exposed to various microbes including the viruses SARS-CoV-2, SARS, and MERS to inactivate them and, thus, protect the lungs and other tissues. This fundamental mechanism seems to be employed by the human body to prevent and protect itself from various invading microbes. Thus, it is reasonable to suggest that a deficiency of AA and other unsaturated fatty acids may render a person susceptible to various infections by viruses such as SARS-CoV-2, SARS, and MERS [138-141].

\section{BALs Prevent Microbial Infection Including SARS-CoV-2}

In addition to their participation in inflammation, resolution of inflammation, and ability to modulate immune response, as discussed above, it is interesting to know that cryoelectron microscopy studies showed that the SARS-CoV-2 spike protein receptor binding domain binds tightly to LA (linoleic acid, 18:2 n-6), an essential fatty acid, rendering it locked in $\mathrm{S}$ conformation that reduces the interaction and binding of the spike protein to ACE2 [142]. This is expected to reduce the infectivity of the SARS-CoV-2. A similar reduced infectivity of MERS-CoV was also noted in relation to LA. This was further supported by the report that ALA, EPA, and DHA (and, possibly, AA in view of their structural similarity, see Figure 14 for the structures of these fatty acids) effectively interfere with the binding of SARS-CoV-2 with human ACE2, the receptor for SARS-CoV-2 [143]. In addition, ALA and EPA not only significantly blocked the entry of SARS-CoV-2 to a spike protein pseudo-virus, but also reduced the activity of TMPRSS2 and cathepsin L-proteases that are needed for the infectivity of SARS-CoV-2. In this study [143], it was noted that LA, ALA, EPA, and DHA could reduce the binding of SARS-CoV-2 to the human ACE2 receptor to $\sim 4-5 \%$ of the control. It is noteworthy that, in cell culture studies, LA synergized with remdesivir in markedly suppressing SARS-CoV-2 replication [142]. Furthermore, it was reported that, when human cells are exposed to SARS-CoV-2 and/or human corona virus 229E (HCoV-229E), the human cells release significant amounts of LA and AA to inactivate the viruses [144,145] (See Figures 15 and 16). It was shown that supplementation of LA and AA to HCoV-229E- and MERS-CoV-infected Huh-7 cells significantly suppressed virus replication. These results imply that BALs can inactivate and decrease the infectivity of SARS-CoV-2 and related viruses. Based on these results, it is suggested that, when human cells are exposed to SARS-CoV-2 virus, activation of PLA2 can occur, which leads to release of LA and AA from the cell membrane phospholipid fraction to specifically inactivate the SARS-CoV-2 and related viruses. In the event this release of LA and AA and other BALs is inadequate, it could result in replication of SARS-CoV2 and result in COVID-2. These results are in support of the proposal that BALs play a significant role in the pathobiology of COVID-2 [138-141].

A

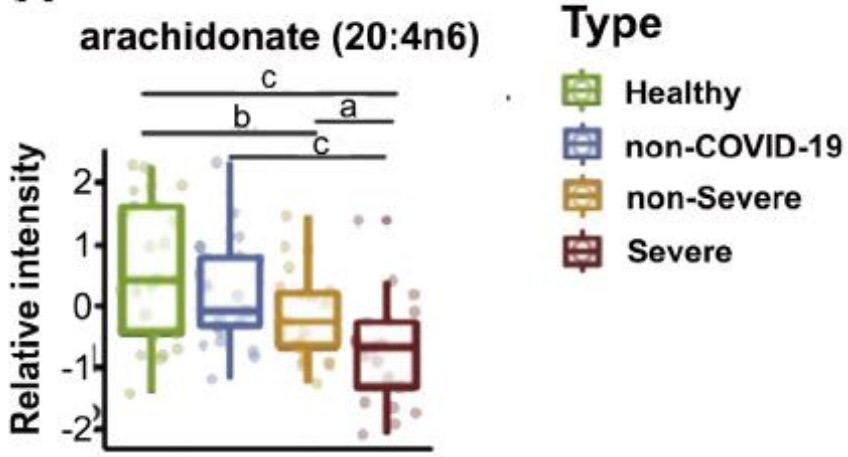

B

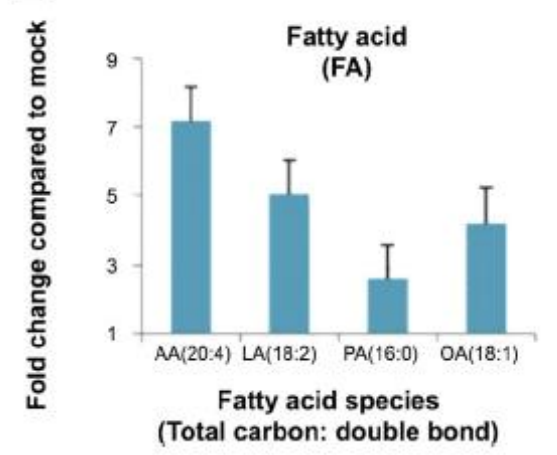

Figure 15. (A) Plasma levels of AA in those infected with SARS-CoV-2. (B) Fold change compared to mock. These results show that those infected with the virus have low levels of AA. These data are taken from Reference [144]. ${ }^{a, b, c} p<0.05$ compared to respective controls, as shown in the figure. 

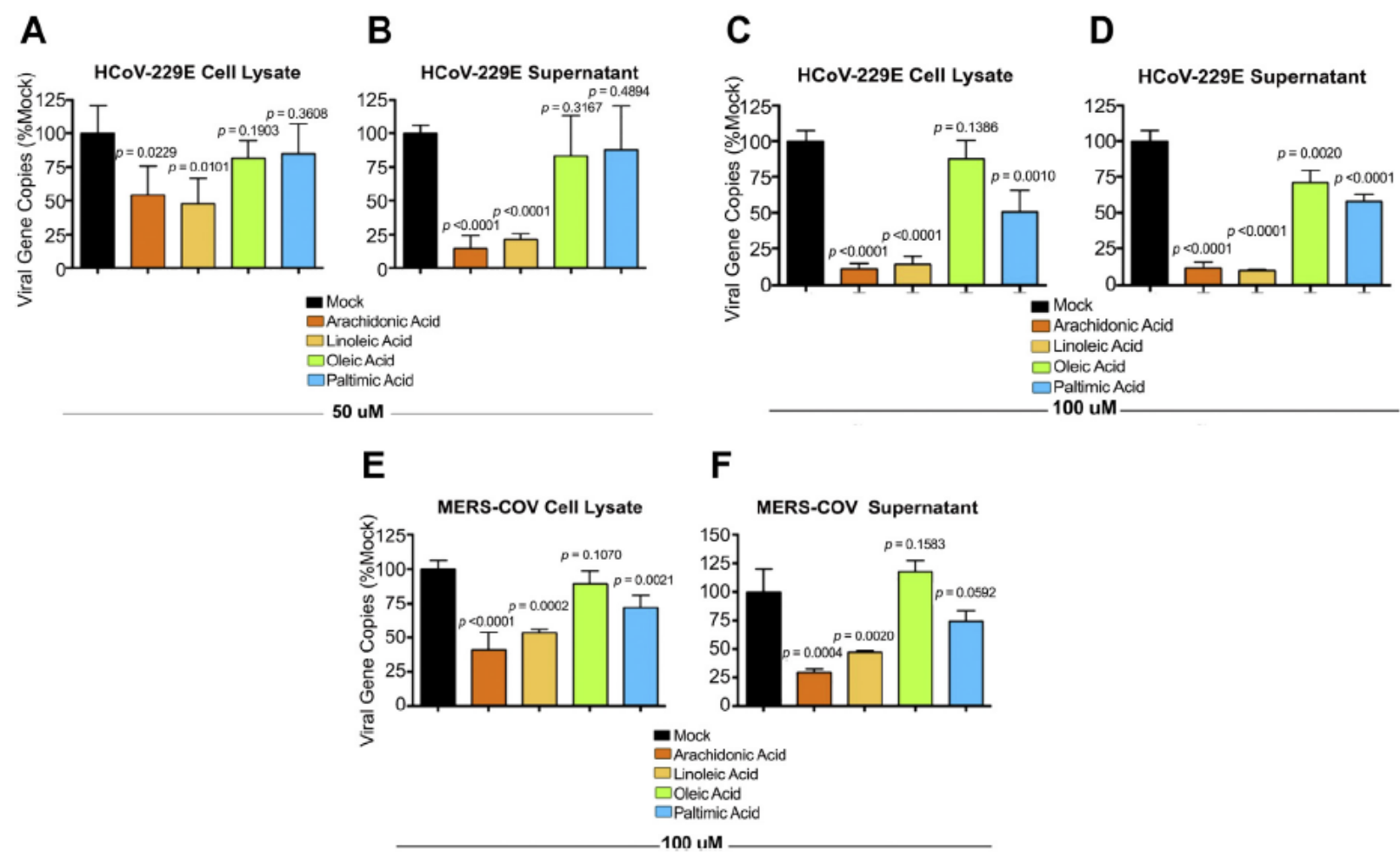

Figure 16. Ability of LA and AA and other fatty acids to inactivate HCoV-229E and MERS-CoV viruses. HuH-7 cells were infected with HCoV-229E or MERS-CoV viruses. After 1 hour of inoculation with the virus, the cells were treated with 50 or $100 \mathrm{mmol}$ of fatty acids for $24 \mathrm{~h}$. Both supernatant and cell lysates were collected and analyzed by RT-qPCR technique. $p<0.05$. These data are taken from reference [145]. (A,B) shows the number of viral gene copies after treatment with $50 \mathrm{uM}$ of various fatty acids of Huh-7 cells infected with $\mathrm{HCoV}-229 \mathrm{E}$ virus in their cell lysate and cell culture supernatant respectively. (C,D) Same study but performed using $100 \mathrm{uM}$ of fatty acids. (E,F) Similar study performed with MERS-CoV virus.

\section{Conclusions and Therapeutic Implications}

Based on the preceding discussion, it is evident that BALs play a significant role in the pathobiology of COVID-19 and similar diseases. BALs (especially DGLA, AA, EPA, and DHA) and their metabolites regulate inflammation and the associated immune response against various invading microbes including SARS-CoV-2 and in the resolution of the inflammation induced by these infections in a timely and regulated fashion. It is important that inflammation needs to occur to an optimum degree so that its resolution is triggered in an orderly fashion. This is clear from the observation that PGE2, a pro-inflammatory molecule that triggers inflammation to start with, can initiate the formation of much needed LXA4 to induce the resolution of inflammation and restore homeostasis. LXA4 not only inhibits PGE2 formation but also suppresses LTB4 (a pro-inflammatory molecule derived from AA and LTB5, derived from EPA) synthesis by enhancing the expression of 5- and 15-lipoxygenases [33-35,39]. Furthermore, resolvins that are needed to induce resolution of inflammation enhance the synthesis of LXA4 [33,35].

PGE2 is not only needed for optimal inflammation but is essential for tissue regeneration [41-45] and to restore homeostasis. This implies that timely administration of AA, the precursor of PGE2 and LXA4, not only suppresses excess production of IL-6 and TNF- $\alpha$ to prevent the 'cytokine storm' seen in moderate to severe cases of COVID-19 but also restores recovery of hematopoiesis and immune response due to suppression of geminal centers seen in them $[4,146,147]$. At this juncture, it is important to note that Garvin et al. [148] proposed that excess bradykinin production causes an increase in vascular dilation, vascular permeability, and hypotension that could be responsible for critical illness in those with COVID-19. Candelario et al. [149] showed that PUFAs increase membrane fluidity and alter B2R (bradykinin 2 receptor) activation (see Figure 17). Of all the unsaturated fatty 
acids tested (especially DGLA, EPA, DHA, and AA), AA was found to suppress bradykinin receptor activation, whereas EPA, DHA, and DGLA activated the same. Based on these results, it is reasonable to propose that AA suppresses bradykinin receptor activation and, thus, inhibits the 'bradykinin' storm. These results, coupled with the observation that BALs (especially LA, ALA, AA, EPA, and DHA) can suppress or inactivate SARS-CoV-2 and similar viruses [142-145], lend further support to the concept that bioactive lipids, especially AA, not only participate in the pathobiology of COVID-19 but also suppress both "cytokine and bradykinin storms".
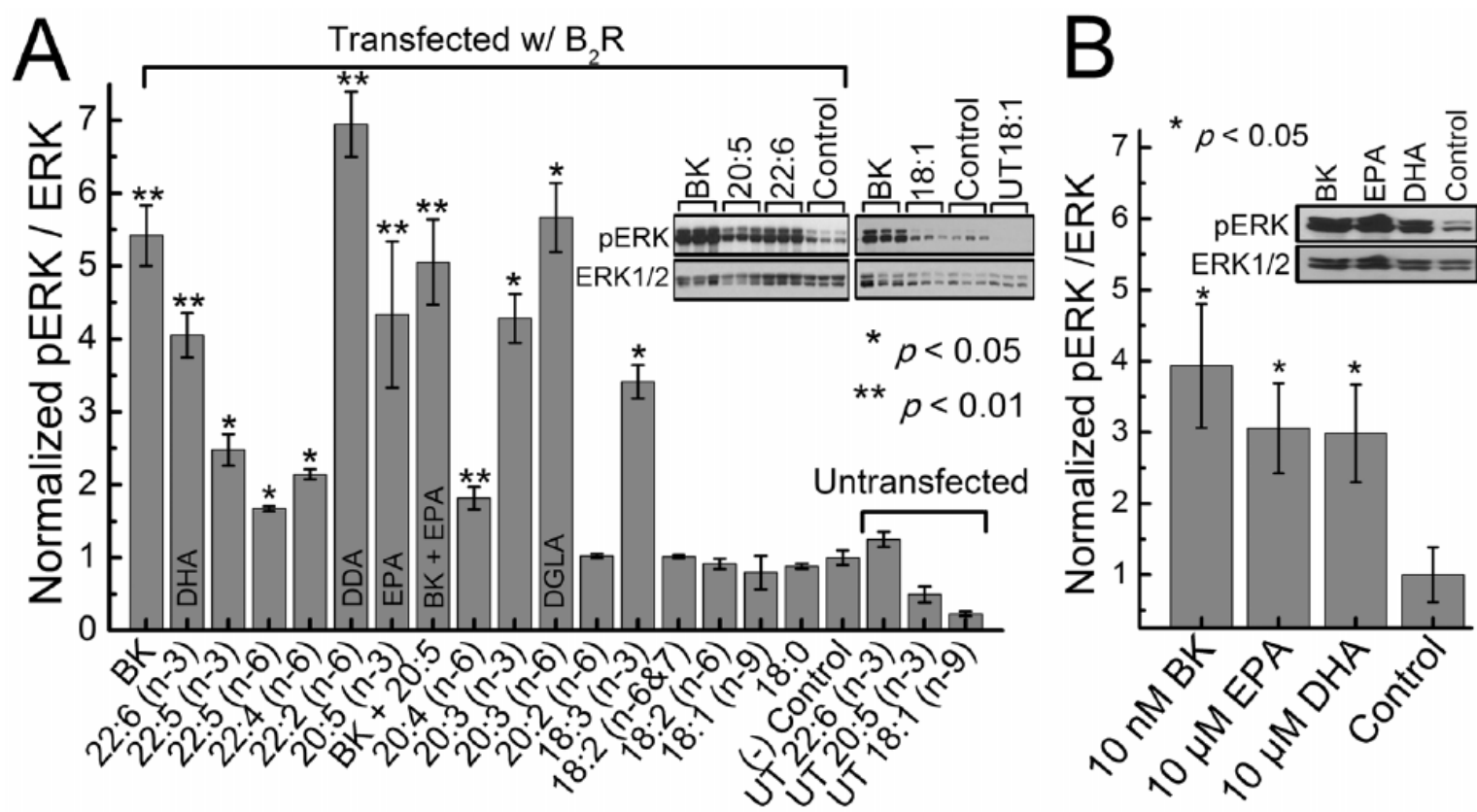

Figure 17. Activation of B2R by various fatty acids in HEK293 cells. Bradykinin concentration in (A) was $100 \mathrm{nM}$ (positive control) and (B) was $10 \mathrm{nM}$. Fatty acid concentrations were $10 \mu \mathrm{M}$ in HEK 293 cells transfected with B2R. It is evident from these studies that, while EPA, DHA, and DGLA significantly enhanced pERK/ERK, AA failed to do so, implying that AA suppresses bradykinin receptor activation, especially in comparison to EPA and DHA. These data are taken from reference [148]. ${ }^{*} p<0.05 ;{ }^{* *} p<0.01$.

Mann et al. [150] presented evidence that those with severe COVID-19 have a shift in the neutrophil-to-T cell ratio, elevated serum IL-6, MCP-1, and IP-10, and modulation of CD14+ monocyte phenotype and function including poor induction of the COX-2 enzyme, implying suboptimal production of PGE2. Longitudinal analysis showed that some of these features revert to normal in those who recovered from the disease. Patients with mild COVID-19 showed higher TNF- $\alpha$ and COX-2 expression in LPS-activated monocytes compared to patients with severe disease. COX-2 expression remained low in severe COVID-19 patients throughout the intensive care period, but levels reverted to normal upon recovery. These results suggest that supplementation of AA may lead to an increase in COX-2 expression and generation of higher amounts of PGE2 that may benefit these patients.

Aging decreases LXA4 levels (LXA4 > resolvins, protectins, and maresins) with a relatively high content of PGs, and thromboxanes that have pro-inflammatory action (see Figure 18) was reported [151], suggesting a decrease in AA content. In such an instance, supplementation of AA with or without EPA/DHA may be necessary to enhance LXA4 formation and suppress inappropriate PGE2 (and other PGs and TXA2 and LTE4) production. Since the decrease in LXA4 formation is more dominant compared to resolvins, protectins, and maresins, perhaps supplementation of only EPA/DHA may be not advisable. 

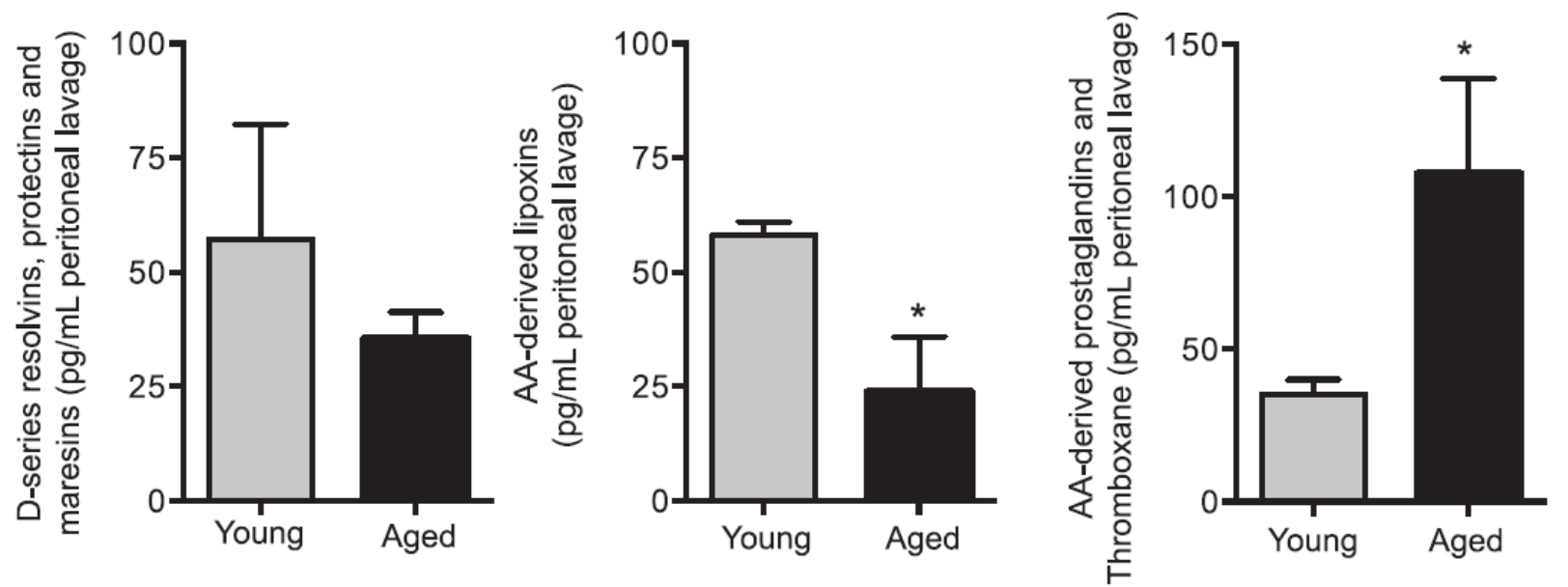

Figure 18. Aged mice show reduced resolvins, protectins, and maresins and LXA4 in the peritoneal lavage of zymosanchallenged animals. ${ }^{*} p<0.05$ compared to young mice. These data are taken from reference [151].

Furthermore, the very occurrence of a 'cytokine storm' in severe COVID-19 is being questioned. It was reported that those who are critically ill due to COVID-19 have much lower levels of cytokines compared to those who have sepsis [5] (see Figure 19). This emphasizes the importance of restoring the concentrations of various lipids including PGE2 and LXA4 to physiological levels that will restore inflammation and immune response abnormalities to normal in COVID-19. These results imply that AA administration may be of significant benefit in other severely ill patients, such as those with sepsis.
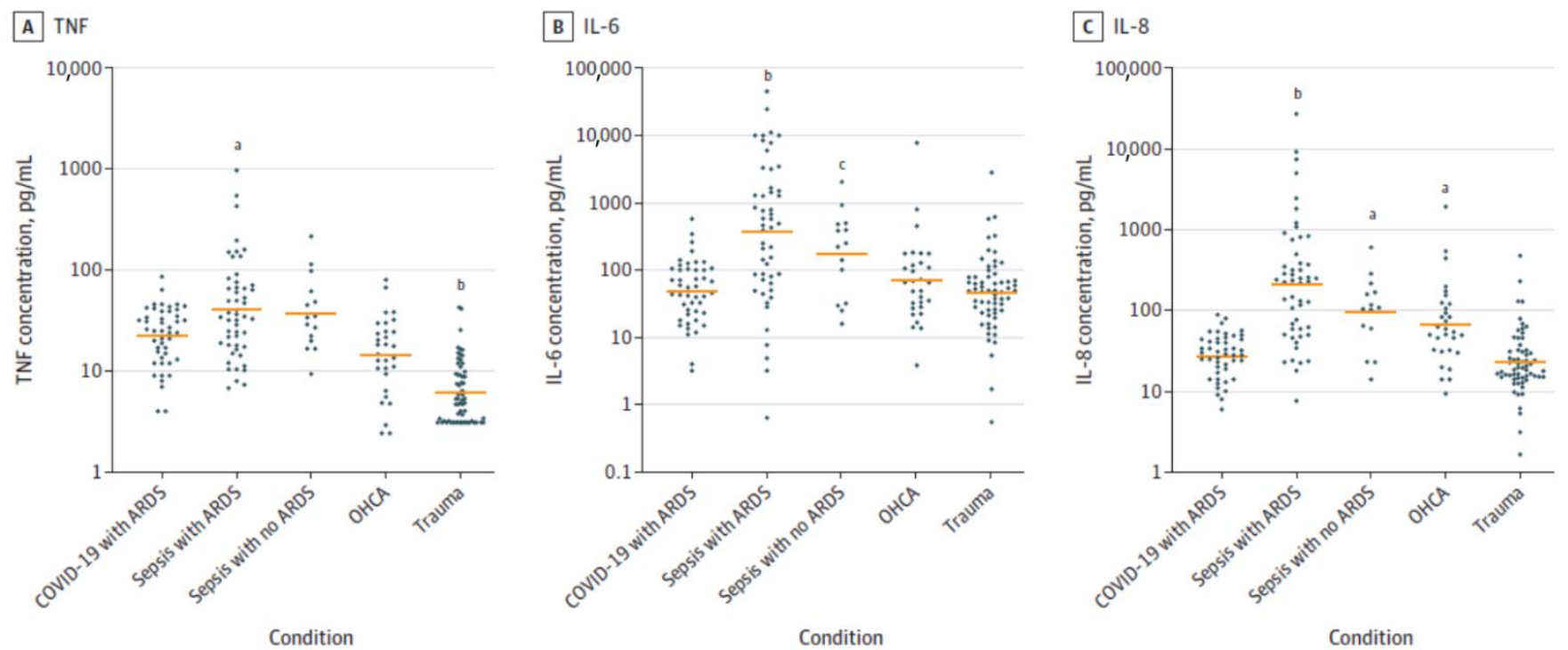

Figure 19. Cytokine levels in critically ill patients with COVID-19 and other conditions. Plasma concentrations of TNF (A), IL-6 (B), and IL-8 (C) in patients with COVID-19 and ARDS $(n=46)$, septic shock with ARDS ( $n=51)$, septic shock without ARDS $(n=15)$, out-of-hospital cardiac arrest (OHCA) $(n=30)$, and multiple traumas $(n=62) .{ }^{\text {a }} p<0.01$ vs. COVID-19 with ARDS; $^{\mathrm{b}} p<0.001$ vs. COVID-19 with ARDS; ${ }^{\mathrm{c}} p<0.05$ vs. COVID-19 with ARDS. These data are taken from reference [5].

It was reported that patients with COVID-19 have a severe deficiency of vitamin C [152]. This suggests that co-administration of vitamin C to those with COVID-19 is important. Vitamin C enhances the formation of PGE1, an anti-inflammatory, anti-platelet anti-aggregator, and modulates immune response [153-155], actions that are remarkably like those shown by LXA4. Insulin has anti-inflammatory actions [156-158]. These results suggest that administration of adequate amounts of AA/EPA/DHA (in the right propor- 
tion), vitamin C, and insulin to those patients with severe COVID-19 may be important even if they are not having significant hyperglycemia.

Subjects with co-morbid conditions such as hypertension, diabetes mellitus, and coronary heart disease are known to have high morbidity and mortality due to COVID-19. Previously, I showed that these patients have low plasma concentrations of AA, EPA, and DHA and, so, are likely to suffer from a deficiency of LXA4, resolvins, protectins, and maresins $[9,11,13-24,55,58,159]$. Once again, this evidence suggests that AA/EPA/DHA deficiency and reduced formation of their anti-inflammatory molecules render them more susceptible to develop COVID-19 and its associated complications.

The proposal made here and elsewhere [138-141] can be verified by studying whether GLA, DGLA, AA, EPA, DHA, LXA4, resolvins, protectin, and maresins can inactivate SARSCoV-2. It is necessary to evaluate the role of desaturases, COX-2, -5 , and -12 , and $15-\mathrm{LOX}$ enzymes and different types of phospholipases in COVID-19. In patients with COVID-19, plasma levels of various EFAs and their metabolites can be measured to know whether their deficiency occurs in COVID-19. Potential therapeutic benefits of EFAs and their metabolites need to be studied in well-designed clinical studies. It is necessary to know whether EFAs and their metabolites influence the development of antibodies against SARS-CoV-2. Since EFAs and their metabolites have a broad spectrum of actions, it is important to design studies with care and arrive at the correct combination of AA/EPA/DHA that can prevent and ameliorate COVID-19.

Funding: No external funding was received for this work.

Conflicts of Interest: The author declares no conflict of interest.

\section{References}

1. Wiersinga, W.J.; Rhodes, A.; Cheng, A.C.; Peacock, S.J.; Prescott, H.C. Pathophysiology, Transmission, Diagnosis, and Treatment of Coronavirus Disease 2019 (COVID-19): A Review. JAMA 2020, 324, 782-793. [CrossRef]

2. Xu, Z.; Shi, L.; Wang, Y.; Zhang, J.; Huang, L.; Zhang, C.; Liu, S.; Zhao, P.; Liu, H.; Zhu, L.; et al. Pathological findings of COVID-19 associated with acute respiratory distress syndrome. Lancet Respir. Med. 2020, 8, 420-422. [CrossRef]

3. Van De Veerdonk, F.L.; Netea, M.G.; Van Deuren, M.; Van Der Meer, J.W.; De Mast, Q.; Brüggemann, R.J.; Van Der Hoeven, H. Kallikrein-kinin blockade in patients with COVID-19 to prevent acute respiratory distress syndrome. eLife 2020, 9, 57555. [CrossRef] [PubMed]

4. Kaneko, N.; Kuo, H.-H.; Boucau, J.; Farmer, J.R.; Allard-Chamard, H.; Mahajan, V.S.; Piechocka-Trocha, A.; Lefteri, K.; Osborn, M.; Bals, J.; et al. Loss of Bcl-6-Expressing T Follicular Helper Cells and Germinal Centers in COVID-19. Cell 2020, 183, 143-157. [CrossRef]

5. Kox, M.; Waalders, N.J.B.; Kooistra, E.J.; Gerretsen, J.; Pickkers, P. Cytokine Levels in Critically Ill Patients With COVID-19 and Other Conditions. JAMA 2020, 324, 1565-1567. [CrossRef]

6. Arunachalam, P.S.; Wimmers, F.; Mok, C.K.P.; Perera, R.A.P.M.; Scott, M.; Hagan, T.; Sigal, N.; Feng, Y.; Bristow, L.; Tsang, O.T.-Y.; et al. Systems biological assessment of immunity to mild versus severe COVID-19 infection in humans. Science 2020, 369, 1210-1220. [CrossRef]

7. Mathew, D.; Giles, J.R.; Baxter, A.E.; Oldridge, D.A.; Greenplate, A.R.; Wu, J.E.; Alanio, C.; Kuri-Cervantes, L.; Pampena, M.B.; D'Andrea, K.; et al. Deep immune profiling of COVID-19 patients reveals distinct immunotypes with therapeutic implications. Science 2020, 369, 8511. [CrossRef]

8. Das, U. "Cell Membrane Theory of Senescence" and the Role of Bioactive Lipids in Aging, and Aging Associated Diseases and their Therapeutic Implications. Biomolecules 2021, 11, 241. [CrossRef] [PubMed]

9. Das, U. Essential fatty acid metabolism in patients with essential hypertension, diabetes mellitus and coronary heart disease. Prostaglandins Leukot. Essent. Fat. Acids 1995, 52, 387-391. [CrossRef]

10. Poorani, R.; Bhatt, A.N.; Dwarakanath, B.; Das, U.N. COX-2, aspirin and metabolism of arachidonic, eicosapentaenoic and docosahexaenoic acids and their physiological and clinical significance. Eur. J. Pharmacol. 2016, 785, 116-132. [CrossRef] [PubMed]

11. Das, U.N. Essential fatty acids and their metabolites could function as endogenous HMG-CoA reductase and ACE enzyme inhibitors, anti-arrhythmic, anti-hypertensive, anti-atherosclerotic, anti-inflammatory, cytoprotective, and cardioprotective molecules. Lipids Health Dis. 2008, 7, 37. [CrossRef]

12. Das, U.N. Bioactive Lipids in Age-Related Disorders. Adv. Exp. Med. Biol. 2020, 1260, 33-83. [CrossRef] [PubMed]

13. Gundala, N.K.V.; Naidu, V.G.M.; Das, U.N. Arachidonic acid and lipoxinA4 attenuate streptozotocin-induced cytotoxicity to RIN5 F cells in vitro and type 1 and type 2 diabetes mellitus in vivo. Nutrition 2017, 35, 61-80. [CrossRef] 
14. Bathina, S.; Gundala, N.K.; Rhenghachar, P.; Polavarapu, S.; Hari, A.D.; Sadananda, M.; Das, U.N. Resolvin D1 Ameliorates Nicotinamide-streptozotocin-induced Type 2 Diabetes Mellitus by its Anti-inflammatory Action and Modulating PI3K/Akt/mTOR Pathway in the Brain. Arch. Med. Res. 2020, 51, 492-503. [CrossRef]

15. Bathina, S.; Das, U. Resolvin D1 Decreases Severity of Streptozotocin-Induced Type 1 Diabetes Mellitus by Enhancing BDNF Levels, Reducing Oxidative Stress, and Suppressing Inflammation. Int. J. Mol. Sci. 2021, 22, 1516. [CrossRef] [PubMed]

16. Haworth, O.; Cernadas, M.; Yang, R.; Serhan, C.N.; Levy, B.D. Resolvin E1 regulates interleukin 23, interferon- $\gamma$ and lipoxin A4 to promote the resolution of allergic airway inflammation. Nat. Immunol. 2008, 9, 873-879. [CrossRef] [PubMed]

17. Gundala, N.K.V.; Naidu, V.G.M.; Das, U.N. Arachidonic acid and lipoxin A4 attenuate alloxan-induced cytotoxicity to RIN5F cellsin vitroand type 1 diabetes mellitusin vivo. BioFactors 2017, 43, 251-271. [CrossRef]

18. Riemersma, R.A.; Wood, D.A.; Butler, S.; Elton, R.A.; Oliver, M.; Salo, M.; Nikkari, T.; Vartiainen, E.; Puska, P.; Gey, F. Linoleic acid content in adipose tissue and coronary heart disease. BMJ 1986, 292, 1423-1427. [CrossRef]

19. Wood, D.; Riemersma, R.; Butler, S.; Thomson, M.; Oliver, M.; Fulton, M.; Birtwhistle, A.; Elton, R. Adipose tissue and platelet fatty acids and coronary heart disease in Scottish men. Lancet 1984, 324, 117-121. [CrossRef]

20. Wood, D.; Butler, S.; Macintyre, C.; Riemersma, R.; Thomson, M.; Elton, R.; Oliver, M. Linoleic and eicosapentaenoic acids in adipose tissue and platelets and risk of coronary heart disease. Lancet 1987, 329, 177-183. [CrossRef]

21. Wood, D.A.; Butler, S.M.; Fulton, M.; Birtwhistle, A.; Riemersma, R.A.; Oliver, M.F.; Elton, R. Does low dietary and serum linoleic acid predispose to myocardial infarction? BMJ 1982, 285, 1738. [CrossRef] [PubMed]

22. Salo, M.K.; Vartiainen, E.; Puska, P.; Nikkari, T. Platelet Aggregation in Finnish Men and Its Relation to Fatty Acids in Platelets, Plasma and Adipose Tissue. Thromb. Haemost. 1985, 54, 563-569. [CrossRef]

23. Das, U.N. Biological significance of arachidonic acid. Med. Sci. Res. 1987, 15, 1485-1490.

24. Willis, A. Dihomo- $\gamma$-Linolenic acid as the endogenous protective agent for myocardial infarction. Lancet 1984, 324, 697. [CrossRef]

25. Juan, H.; Sametz, W. Dihomo- $\delta$-linolenic acid increases the metabolism of eicosapentaenoic acid in perfused vascular tissue. Prostaglandins Leukot. Med. 1985, 19, 79-86. [CrossRef]

26. Dooper, M.M.B.W.; Van Riel, B.; Graus, Y.M.F.; M'Rabet, L. Dihomo- $\gamma$-linolenic acid inhibits tumour necrosis factor- $\alpha$ production by human leucocytes independently of cyclooxygenase activity. Immunology 2003, 110, 348-357. [CrossRef]

27. Cao, D.; Luo, J.; Zang, W.; Chen, D.; Xu, H.; Shi, H.; Jing, X. Gamma-Linolenic Acid Suppresses NF-kB Signaling via CD36 in the Lipopolysaccharide-Induced Inflammatory Response in Primary Goat Mammary Gland Epithelial Cells. Inflammation 2016, 39, 1225-1237. [CrossRef] [PubMed]

28. Chang, C.-S.; Sun, H.-L.; Lii, C.-K.; Chen, H.-W.; Chen, P.-Y.; Liu, K.-L. Gamma-Linolenic Acid Inhibits Inflammatory Responses by Regulating NF-kB and AP-1 Activation in Lipopolysaccharide-Induced RAW 264.7 Macrophages. Inflammation 2010, 33 , 46-57. [CrossRef]

29. Kapoor, R. Gamma Linolenic Acid: An Antiinflammatory Omega-6 Fatty Acid. Curr. Pharm. Biotechnol. 2006, 7, 531-534. [CrossRef]

30. Chen, P.-Y.; Wang, J.; Lin, Y.-C.; Li, C.-C.; Tsai, C.-W.; Liu, T.-C.; Chen, H.-W.; Huang, C.-S.; Lii, C.-K.; Liu, K.-L. 18-Carbon polyunsaturated fatty acids ameliorate palmitate-induced inflammation and insulin resistance in mouse C2C12 myotubes. J. Nutr. Biochem. 2015, 26, 521-531. [CrossRef]

31. Novak, F.; Vecka, M.; Meisnerova, E.; Sevela, S.; Vavrova, L.; Rychlikova, J.; Dolezalova, L.; Myslivcova, D.; Zak, A.; Vitek, L.; et al Fish oil supplementation with various lipid emulsions suppresses in vitro cytokine release in home parenteral nutrition patients: A crossover study. Nutr. Res. 2019, 72, 70-79. [CrossRef]

32. Hao, W.; Wong, O.Y.; Liu, X.; Lee, P.; Chen, Y.; Wong, K.K. $\omega$-3 fatty acids suppress inflammatory cytokine production by macrophages and hepatocytes. J. Pediatr. Surg. 2010, 45, 2412-2418. [CrossRef] [PubMed]

33. Das, U.N. Current and emerging strategies for the treatment and management of systemic lupus erythematosus based on mo-lecular signatures of acute and chronic inflammation. J. Inflamm. Res. 2010, 3, 143-170. [CrossRef]

34. Loynes, C.A.; Lee, J.A.; Robertson, A.L.; Steel, M.J.; Ellett, F.; Feng, Y.; Levy, B.D.; Whyte, M.K.; Renshaw, S.A. PGE 2 production at sites of tissue injury promotes an anti-inflammatory neutrophil phenotype and determines the outcome of inflammation resolution in vivo. Sci. Adv. 2018, 4, eaar8320. [CrossRef]

35. Chan, M.M.-Y.; Moore, A.R. Resolution of inflammation in murine autoimmune arthritis is disrupted by cyclooxygenase-2 inhibi-tion and restored by prostaglandin E2-mediated lipoxin A4 production. J. Immunol. 2010, 184, 6418-6426. [CrossRef] [PubMed]

36. Gilroy, D.; Colvillenash, P.R.; Willis, D.K.; Chivers, J.; Paulclark, M.J.; Willoughby, D. Inducible cyclooxygenase may have anti-inflammatory properties. Nat. Med. 1999, 5, 698-701. [CrossRef] [PubMed]

37. Gobbetti, T.; Le Faouder, P.; Bertrand, J.; Dubourdeau, M.; Barocelli, E.; Cenac, N.; Vergnolle, N. Polyunsaturated Fatty Acid Metabolism Signature in Ischemia Differs from Reperfusion in Mouse Intestine. PLoS ONE 2013, 8, e75581. [CrossRef]

38. Gobbetti, T.; Ducheix, S.; Le Faouder, P.; Perez-Berezo, T.; Riols, F.; Boue, J.; Bertrand-Michel, J.; Dubourdeau, M.; Guillou, H.; Perretti, M.; et al. Protective effects of n-6 fatty acids-enriched diet on intestinal ischaemia/reperfusion injury involve lipoxin A4and its receptor. Br. J. Pharmacol. 2014, 172, 910-923. [CrossRef] [PubMed]

39. Duffin, R.; O'Connor, R.A.; Crittenden, S.; Forster, T.; Yu, C.; Zheng, X.; Smyth, D.; Robb, C.T.; Rossi, F.; Skouras, C.; et al. Prostaglandin E 2 constrains systemic inflammation through an innate lymphoid cell-IL-22 axis. Science 2016, 351, 1333-1338. [CrossRef] [PubMed] 
40. Motwani, M.P.; Colas, R.A.; George, M.J.; Flint, J.D.; Dalli, J.; Richard-Loendt, A.; De Maeyer, R.; Serhan, C.N.; Gilroy, D.W. Pro-resolving mediators promote resolution in a human skin model of UV-killed Escherichia coli-driven acute inflammation. JCI Insight 2018, 3, 94463. [CrossRef]

41. Zhang, Y.; Desai, A.; Yang, S.Y.; Bae, K.B.; Antczak, M.I.; Fink, S.P.; Tiwari, S.; Willis, J.E.; Williams, N.S.; Dawson, D.M.; et al. Inhibition of the prostaglandin-degrading enzyme 15-PGDH potentiates tissue regeneration. Science 2015, 348, aaa2340. [CrossRef] [PubMed]

42. Diaz, M.F.; Li, N.; Lee, H.J.; Adamo, L.; Evans, S.M.; Willey, H.; Arora, N.; Torisawa, Y.-S.; Vickers, D.A.; Morris, S.A.; et al. Biomechanical forces promote blood development through prostaglandin E2 and the cAMP-PKA signaling axis. J. Exp. Med. 2015, 212, 665-680. [CrossRef] [PubMed]

43. North, T.E.; Goessling, W.; Walkley, C.; Lengerke, C.; Kopani, K.R.; Lord, A.M.; Weber, G.J.; Bowman, T.V.; Jang, I.-H.; Grosser, T.; et al. Prostaglandin E2 regulates vertebrate haematopoietic stem cell homeostasis. Nat. Cell Biol. 2007, 447, 1007-1011. [CrossRef]

44. Hoggatt, J.; Mohammad, K.S.; Singh, P.; Hoggatt, A.F.; Chitteti, B.R.; Speth, J.; Hu, P.; Poteat, B.A.; Stilger, K.N.; Ferraro, F.; et al. Differential stem- and progenitor-cell trafficking by prostaglandin E2. Nat. Cell Biol. 2013, 495, 365-369. [CrossRef]

45. Hoggatt, J.; Singh, P.; Sampath, J.; Pelus, L.M. Prostaglandin E2 enhances hematopoietic stem cell homing, survival, and proliferation. Blood 2009, 113, 5444-5455. [CrossRef]

46. Ikushima, Y.M.; Arai, F.; Hosokawa, K.; Toyama, H.; Takubo, K.; Furuyashiki, T.; Narumiya, S.; Suda, T. Prostaglandin E2 regulates murine hematopoietic stem/progenitor cells directly via EP4 receptor and indirectly through mesenchymal progenitor cells. Blood 2013, 121, 1995-2007. [CrossRef] [PubMed]

47. Simões, R.L.; De-Brito, N.M.; Cunha-Costa, H.; Morandi, V.; Fierro, I.M.; Roitt, I.M.; Barja-Fidalgo, C. Lipoxin A4selectively programs the profile of M2 tumor-associated macrophages which favour control of tumor progression. Int. J. Cancer 2016, 140, 346-357. [CrossRef]

48. Bi, C.; Fu, Y.; Zhang, Z.; Li, B. Prostaglandin E2 confers protection against diabetic coronary atherosclerosis by stimulating M2 macrophage polarization via the activation of the CREB/BDNF/TrkB signaling pathway. FASEB J. 2020, 34, 7360-7371. [CrossRef]

49. Yang, X.; Li, S.; Zhao, Y.; Li, S.; Zhao, T.; Tai, Y.; Zhang, B.; Wang, X.; Wang, C.; Chen, J.; et al. GRK2 Mediated Abnormal Transduction of PGE2-EP4-cAMP-CREB Signaling Induces the Imbalance of Macrophages Polarization in Collagen-Induced Arthritis Mice. Cells 2019, 8, 1596. [CrossRef]

50. Luan, B.; Yoon, Y.-S.; Le Lay, J.; Kaestner, K.H.; Hedrick, S.; Montminy, M. CREB pathway links PGE2 signaling with macrophage polarization. Proc. Natl. Acad. Sci. USA 2015, 112, 15642-15647. [CrossRef]

51. Lu, L.Y.; Loi, F.; Nathan, K.; Lin, T.-H.; Pajarinen, J.; Gibon, E.; Nabeshima, A.; Cordova, L.; Jämsen, E.; Yao, Z.; et al. Proinflammatory M1 macrophages promote Osteogenesis by mesenchymal stem cells via the COX-2-prostaglandin E2 pathway. J. Orthop. Res. 2017, 35, 2378-2385. [CrossRef] [PubMed]

52. Zhang, S.; Liu, Y.; Zhang, X.; Zhu, D.; Qi, X.; Cao, X.; Fang, Y.; Che, Y.; Han, Z.-C.; He, Z.-X.; et al. Prostaglandin E2 hydrogel improves cutaneous wound healing via M2 macrophages polarization. Theranostics 2018, 8, 5348-5361. [CrossRef]

53. Dalli, J.; Zhu, M.; Vlasenko, N.A.; Deng, B.; Haeggström, J.Z.; Petasis, N.A.; Serhan, C.N. The novel 13 S, 14 S-epoxy-maresin is converted by human macrophages to maresin 1 (MaR1), inhibits leukotriene A 4 hydrolase (LTA 4 H), and shifts macrophage phenotype. FASEB J. 2013, 27, 2573-2583. [CrossRef]

54. Nelson, A.J.; Stephenson, D.J.; Cardona, C.; Lei, X.; Almutairi, A.; White, T.D.; Tusing, Y.G.; Park, M.A.; Barbour, S.E.; Chalfant, C.E.; et al. Macrophage polarization is linked to Ca2+-independent phospholipase A2 $\beta$-derived lipids and cross-cell signaling in mice. J. Lipid Res. 2020, 61, 143-158. [CrossRef]

55. Naveen, K.V.G.; Naidu, V.G.M.; Das, U.N. Amelioration of streptozotocin-induced type 2 diabetes mellitus in Wistar rats by ara-chidonic acid. Biochem. Biophys. Res. Commun. 2018, 496, 105-113.

56. Das, U.N. Molecular Biochemical Aspects of Cancer; Humana Press: New York, NY, USA, 2020.

57. Das, U.N. Molecular Basis of Health and Disease; Springer: New York, NY, USA, 2011.

58. Serhan, C.N.; Hamberg, M.; Samuelsson, B. Lipoxins: Novel series of biologically active compounds formed from arachidonic acid in human leukocytes. Proc. Natl. Acad. Sci. USA 1984, 81, 5335-5339. [CrossRef]

59. Serhan, C.N.; Samuelsson, B. Lipoxins: A New Series of Eicosanoids (Biosynthesis, Stereochemistry, and Biological Activities). Lipoxins 1988, 229, 1-14. [CrossRef]

60. Harris, W.S.; Mozaffarian, D.; Rimm, E.; Kris-Etherton, P.; Rudel, L.L.; Appel, L.J.; Engler, M.M.; Engler, M.B.; Sacks, F. Omega-6 fatty acids and risk for cardiovascular disease: A science advisory from the American Heart Association Nutrition Subcommittee of the Council on Nutrition, Physical Activity, and Metabolism; Council on Cardiovascular Nursing; and Council on Epidemiology and Prevention. Circulation 2009, 119, 902-907. [CrossRef] [PubMed]

61. Giamarellos-Bourboulis, E.; Mouktaroudi, M.; Adamis, T.; Koussoulas, V.; Baziaka, F.; Perrea, D.; Karayannacos, P.E.; Giamarellou, H. n-6 Polyunsaturated Fatty Acids Enhance the Activities of Ceftazidime and Amikacin in Experimental Sepsis Caused by Multidrug-Resistant Pseudomonas aeruginosa. Antimicrob. Agents Chemother. 2004, 48, 4713-4717. [CrossRef]

62. Tateishi, N.; Kakutani, S.; Kawashima, H.; Shibata, H.; Morita, I. Dietary supplementation of arachidonic acid increases arachidonic acid and lipoxin A4 contents in colon, but does not affect severity or prostaglandin E2 content in murine colitis model. Lipids Health Dis. 2014, 13, 30. [CrossRef] 
63. Tateishi, N.; Kaneda, Y.; Kakutani, S.; Kawashima, H.; Shibata, H.; Morita, I. Dietary supplementation with arachidonic acid increases arachidonic acid content in paw, but does not affect arthritis severity or prostaglandin E2 content in rat adjuvant-induced arthritis model. Lipids Health Dis. 2015, 14, 3. [CrossRef] [PubMed]

64. Kakutani, S.; Ishikura, Y.; Tateishi, N.; Horikawa, C.; Tokuda, H.; Kontani, M.; Kawashima, H.; Sakakibara, Y.; Kiso, Y.; Shibata, H.; et al. Supplementation of arachidonic acid-enriched oil increases arachidonic acid contents in plasma phospholipids, but does not increase their metabolites and clinical parameters in Japanese healthy elderly individuals: A randomized controlled study. Lipids Health Dis. 2011, 10, 241. [CrossRef] [PubMed]

65. Ortsäter, H. Arachidonic acid fights palmitate: New insights into fatty acid toxicity in $\beta$-cells. Clin. Sci. 2010, 120, 179-181. [CrossRef]

66. Keane, D.C.; Takahashi, H.K.; Dhayal, S.; Morgan, N.G.; Curi, R.; Newsholme, P. Arachidonic acid actions on functional in-tegrity and attenuation of the negative effects of palmitic acid in a clonal pancreatic $\beta$-cell line. Clin. Sci. 2011, 120, 195-206. [CrossRef] [PubMed]

67. Cho, Y.S.; Kim, C.H.; Kim, K.Y.; Cheon, H.G. Protective effects of arachidonic acid against palmitic acid-mediated lipotoxicity in HIT-T15 cells. Mol. Cell. Biochem. 2012, 364, 19-28. [CrossRef] [PubMed]

68. Naveen, G.V.; Das, U.N. Arachidonic acid rich ARASCO oil has anti-inflammatory and anti-diabetic actions against high fat diet-induced type 2 diabetes mellitus in Wistar rats. Nutrition 2019, 66, 203-218.

69. Vasandan, A.B.; Jahnavi, S.; Shashank, C.; Prasad, P.; Kumar, A.; Prasanna, S.J. Human Mesenchymal stem cells program macrophage plasticity by altering their metabolic status via a PGE2-dependent mechanism. Sci. Rep. 2016, 6, 38308. [CrossRef] [PubMed]

70. Park, H.J.; Kim, J.; Saima, F.T.; Rhee, K.-J.; Hwang, S.; Kim, M.Y.; Baik, S.K.; Eom, Y.W.; Kim, H.-S. Adipose-derived stem cells ameliorate colitis by suppression of inflammasome formation and regulation of M1-macrophage population through prostaglandin E2. Biochem. Biophys. Res. Commun. 2018, 498, 988-995. [CrossRef]

71. An, J.-H.; Song, W.-J.; Li, Q.; Kim, S.-M.; Yang, J.-I.; Ryu, M.-O.; Nam, A.R.; Bhang, D.H.; Jung, Y.-C.; Youn, H.-Y. Prostaglandin E2 secreted from feline adipose tissue-derived mesenchymal stem cells alleviate DSS-induced colitis by increasing regulatory $\mathrm{T}$ cells in mice. BMC Vet.-Res. 2018, 14, 354. [CrossRef]

72. Rozenberg, A.; Rezk, A.; Boivin, M.-N.; Darlington, P.; Nyirenda, M.; Li, R.; Jalili, F.; Winer, R.; Artsy, E.A.; Uccelli, A.; et al. Human Mesenchymal Stem Cells Impact Th17 and Th1 Responses Through a Prostaglandin E2 and Myeloid-Dependent Mechanism. Stem Cells Transl. Med. 2016, 5, 1506-1514. [CrossRef]

73. Phipps, R.P.; Stein, S.H.; Roper, R. A new view of prostaglandin E regulation of the immune response. Immunol. Today 1991, 12, 349-352. [CrossRef]

74. Németh, K.; Leelahavanichkul, A.; Yuen, P.; Mayer, B.; Parmelee, A.; Doi, K.; Robey, P.; Leelahavanichkul, K.; Koller, B.H.; Brown, J.M.; et al. Bone marrow stromal cells attenuate sepsis via prostaglandin E2-dependent reprogramming of host macrophages to increase their interleukin-10 production. Nat. Med. 2008, 15, 42-49. [CrossRef]

75. Ylöstalo, J.H.; Bartosh, T.J.; Coble, K.; Prockop, D.J. Human Mesenchymal Stem/Stromal Cells Cultured as Spheroids are Self-activated to Produce Prostaglandin E2 that Directs Stimulated Macrophages into an Anti-inflammatory Phenotype. Stem Cells 2012, 30, 2283-2296. [CrossRef]

76. Poloso, N.J.; Urquhart, P.; Nicolaou, A.; Wang, J.; Woodward, D.F. PGE2 differentially regulates monocyte-derived dendritic cell cytokine responses depending on receptor usage (EP2/EP4). Mol. Immunol. 2013, 54, 284-295. [CrossRef]

77. Lee, J.Y.; Jung, Y.W.; Jeong, I.; Joh, J.-S.; Sim, S.Y.; Choi, B.; Jee, H.-G.; Lim, D.-G. Immune parameters differentiating active from latent tuberculosis infection in humans. Tuberculosis 2015, 95, 758-763. [CrossRef] [PubMed]

78. Kim, K.; Perera, R.; Tan, D.; Fernandez, S.; Seddiki, N.; Waring, J.; French, M. Circulating mycobacterial-reactive CD4+ T cells with an immunosuppressive phenotype are higher in active tuberculosis than latent tuberculosis infection. Tuberculosis 2014, 94, 494-501. [CrossRef] [PubMed]

79. Marin, N.D.; París, S.C.; Vélez, V.M.; Rojas, C.A.; Rojas, M.; García, L.F. Regulatory T cell frequency and modulation of IFN-gamma and IL-17 in active and latent tuberculosis. Tuberculosis 2010, 90, 252-261. [CrossRef] [PubMed]

80. Gerosa, F.; Nisii, C.; Righetti, S.; Micciolo, R.; Marchesini, M.; Cazzadori, A.; Trinchieri, G. CD4(+) T cell clones producing both inter-feron-gamma and interleukin-10 predominate in bronchoalveolar lavages of active pulmonary tuberculosis patients. Clin. Immunol. 1999, 92, 224-234. [CrossRef] [PubMed]

81. Berner, B.; Akça, D.; Jung, T.; Muller, G.A.; Reuss-Borst, M.A. Analysis of Th1 and Th2 cytokines expressing CD4+ and CD8+ T cells in rheumatoid arthritis by flow cytometry. J. Rheumatol. 2000, 27, 1128-1135. [PubMed]

82. Khader, S.A.; Cooper, A.M. IL-23 and IL-17 in tuberculosis. Cytokine 2008, 41, 79-83. [CrossRef]

83. Wei, L.; Liu, M.; Xiong, H.; Peng, B. Up-regulation of IL-23 expression in human dental pulp fibroblasts by IL-17 via activation of the NF-kB and MAPK pathways. Int. Endod. J. 2018, 51, 622-631. [CrossRef]

84. Zhu, L.; Wu, Y.; Wei, H.; Xing, X.; Zhan, N.; Xiong, H.; Peng, B. IL-17R activation of human periodontal ligament fibroblasts induces IL-23 p19 production: Differential involvement of NF-kB versus JNK/AP-1 pathways. Mol. Immunol. 2011, 48, 647-656. [CrossRef]

85. Liu, F.L.; Chen, C.H.; Chu, S.J.; Chen, J.H.; Lai, J.H.; Sytwu, H.K.; Chang, D.M. Interleukin (IL)-23 p19 expression induced by IL-1beta in human fibroblast-like synoviocytes with rheumatoid arthritis via active nuclear factor-kappaB and AP-1 dependent pathway. Rheumatology 2007, 46, 1266-1273. [CrossRef] 
86. Kim, H.-R.; Cho, M.-L.; Kim, K.-W.; Juhn, J.-Y.; Hwang, S.-Y.; Yoon, C.-H.; Park, S.-H.; Lee, S.-H. Up-regulation of IL-23p19 expression in rheumatoid arthritis synovial fibroblasts by IL-17 through PI3-kinase-, NF- B- and p38 MAPK-dependent signalling pathways. Rheumatology 2007, 46, 57-64. [CrossRef] [PubMed]

87. Rodríguez, M.; Domingo, E.; Municio, C.; Alvarez, Y.; Hugo, E.; Fernández, M.N.; Crespo, M.S. Polarization of the Innate Immune Response by Prostaglandin E2: A Puzzle of Receptors and Signals. Mol. Pharmacol. 2013, 85, 187-197. [CrossRef]

88. Das, U.N. Molecular pathobiology of scleritis and its therapeutic implications. Int. J. Ophthalmol. 2020, 13, 163-175. [CrossRef]

89. Das, U.N. Bioactive lipids in intervertebral disc degeneration and its therapeutic implications. Biosci. Rep. 2019, $39,20192117$. [CrossRef]

90. Shibabaw, T. Inflammatory Cytokine: IL-17A Signaling Pathway in Patients Present with COVID-19 and Current Treatment Strategy. J. Inflamm. Res. 2020, 13, 673-680. [CrossRef]

91. Schett, G.; Sticherling, M.; Neurath, M.F. COVID-19: Risk for cytokine targeting in chronic inflammatory diseases? Nat. Rev. Immunol. 2020, 20, 271-272. [CrossRef] [PubMed]

92. Sarmiento-Monroy, J.C.; Parra-Medina, R.; Garavito, E.; Rojas-Villarraga, A. T Helper 17 Response to Severe Acute Respiratory Syndrome Coronavirus 2: A Type of Immune Response with Possible Therapeutic Implications. Viral Immunol. 2021, 34, 190-200. [CrossRef] [PubMed]

93. Orlov, M.; Wander, P.L.; Morrell, E.D.; Mikacenic, C.; Wurfel, M.M. A Case for Targeting Th17 Cells and IL-17A in SARS-CoV-2 Infections. J. Immunol. 2020, 205, 892-898. [CrossRef] [PubMed]

94. Wu, D.; Yang, X.O. TH17 responses in cytokine storm of COVID-19: An emerging target of JAK2 inhibitor Fedratinib. J. Microbiol. Immunol. Infect. 2020, 53, 368-370. [CrossRef] [PubMed]

95. Wang, S.; Wang, G.; Zhang, L.; Li, F.; Liu, K.; Wang, Y.; Shi, Y.; Cao, K. Interleukin-17 promotes nitric oxide-dependent expression of PD-L1 in mesenchymal stem cells. Cell Biosci. 2020, 10, 1-11. [CrossRef] [PubMed]

96. Miljkovic, D.; Trajkovic, V. Inducible nitric oxide synthase activation by interleukin-17. Cytokine Growth Factor Rev. 2004, 15, 21-32. [CrossRef] [PubMed]

97. Miljkovic, D.; Cvetkovic, I.; Vuckovic, O.; Stosic-Grujicic, S.; Mostarica Stojkovic, M.; Trajkovic, V. The role of interleukin-17 in inducible nitric oxide synthase-mediated nitric oxide production in endothelial cells. Cell Mol. Life Sci. 2003, 60, 518-525. [CrossRef] [PubMed]

98. Han, X.; Yang, Q.; Lin, L.; Xu, C.; Zheng, C.; Chen, X.; Han, Y.; Li, M.; Cao, W.; Cao, K.; et al. Interleukin-17 enhances immunosuppression by mesenchymal stem cells. Cell Death Differ. 2014, 21, 1758-1768. [CrossRef] [PubMed]

99. Xu, J.; Duan, X.; Hu, F.; Poorun, D.; Liu, X.; Wang, X.; Zhang, S.; Gan, L.; He, M.; Zhu, K.; et al. Resolvin D1 attenuates imiquimod-induced mice psoriasiform dermatitis through MAPKs and NF-kB pathways. J. Dermatol. Sci. 2018, 89, 127-135. [CrossRef]

100. Oner, F.; Alvarez, C.; Yaghmoor, W.; Stephens, D.; Hasturk, H.; Firatli, E.; Kantarci, A. Resolvin E1 Regulates Th17 Function and T Cell Activation. Front. Immunol. 2021, 12, 637983. [CrossRef]

101. Funaki, Y.; Hasegawa, Y.; Okazaki, R.; Yamasaki, A.; Sueda, Y.; Yamamoto, A.; Yanai, M.; Fukushima, T.; Harada, T.; Makino, H.; et al. Resolvin E1 Inhibits Osteoclastogenesis and Bone Resorption by Suppressing IL-17-induced RANKL Expression in Osteo-blasts and RANKL-induced Osteoclast Differentiation. Yonago Acta Med. 2018, 61, 8-18. [CrossRef]

102. Wang, H.; Shi, P.; Huang, C.; Liu, Q. Maresin 1 ameliorates iron-deficient anemia in IL-10(-/-) mice with spontaneous colitis by the inhibition of hepcidin expression though the IL-6/STAT3 pathway. Am. J. Transl. Res. 2016, 8, $2758-2766$.

103. Kurtoğlu, E.L.; Kayhan, B.; Gül, M.; Kayhan, B.; Kayhan, M.A.; Karaca, Z.M.; Yeşilada, E.; Yılmaz, S. A bioactive product lipoxin A4 at-tenuates liver fibrosis in an experimental model by regulating immune response and modulating the expression of regeneration genes. Turk. J. Gastroenterol. 2019, 30, 745-757. [CrossRef] [PubMed]

104. Fang, X.; Abbott, J.; Cheng, L.; Colby, J.K.; Lee, J.W.; Levy, B.D.; Matthay, M.A. Human Mesenchymal Stem (Stromal) Cells Promote the Resolution of Acute Lung Injury in Part through Lipoxin A4. J. Immunol. 2015, 195, 875-881. [CrossRef] [PubMed]

105. Cheng, X.; He, S.; Yuan, J.; Miao, S.; Gao, H.; Zhang, J.; Li, Y.; Peng, W.; Wu, P. Lipoxin A4 attenuates LPS-induced mouse acute lung injury via Nrf2-mediated E-cadherin expression in airway epithelial cells. Free Radic. Biol. Med. 2016, 93, 52-66. [CrossRef]

106. Leng, Z.; Zhu, R.; Hou, W.; Feng, Y.; Yang, Y.; Han, Q.; Shan, G.; Meng, F.; Du, D.; Wang, S.; et al. Transplantation of ACE2Mesenchymal Stem Cells Improves the Outcome of Patients with COVID-19 Pneumonia. Aging Dis. 2020, 11, 216-228. [CrossRef] [PubMed]

107. Wang, Y.; Chen, X.; Cao, W.; Shi, Y. Plasticity of mesenchymal stem cells in immunomodulation: Pathological and thera-peutic implications. Nat. Immunol. 2014, 15, 1009-1016. [CrossRef] [PubMed]

108. Abdelmawgoud, H.; Saleh, A. Anti-inflammatory and antioxidant effects of mesenchymal and hematopoietic stem cells in a rheumatoid arthritis rat model. Adv. Clin. Exp. Med. 2018, 27, 873-880. [CrossRef]

109. Zhang, Z.; Huang, S.; Wu, S.; Qi, J.; Li, W.; Liu, S.; Cong, Y.; Chen, H.; Lu, L.; Shi, S.; et al. Clearance of apoptotic cells by mesenchymal stem cells contributes to immunosuppression via PGE2. EBioMedicine 2019, 45, 341-350. [CrossRef]

110. Holopainen, M.; Colas, R.A.; Valkonen, S.; Tigistu-Sahle, F.; Hyvärinen, K.; Mazzacuva, F.; Lehenkari, P.; Käkelä, R.; Dalli, J.; Kerkelä, E.; et al. Polyunsaturated fatty acids modify the extracellular vesicle membranes and increase the production of proresolving lipid mediators of human mesenchymal stromal cells. Biochim. Biophys. Acta (BBA)-Mol. Cell Biol. Lipids 2019, 1864, 1350-1362. [CrossRef] 
111. Hyvärinen, K.; Holopainen, M.; Skirdenko, V.; Ruhanen, H.; Lehenkari, P.; Korhonen, M.; Käkelä, R.; Laitinen, S.; Kerkelä, E. Mesen-chymal Stromal Cells and Their Extracellular Vesicles Enhance the Anti-Inflammatory Phenotype of Regulatory Macrophages by Downregulating the Production of Interleukin (IL)-23 and IL-22. Front. Immunol. 2018, 8, 771. [CrossRef]

112. Yang, F.Y.; Chen, R.; Zhang, X.; Huang, B.; Tsang, L.L.; Li, X.; Jiang, X. Preconditioning Enhances the Therapeutic Effects of Mesenchymal Stem Cells on Colitis Through PGE2-Mediated T-Cell Modulation. Cell Transplant. 2018, 27, 1352-1367. [CrossRef]

113. Yang, H.M.; Song, W.J.; Li, Q.; Kim, S.Y.; Kim, H.J.; Ryu, M.O.; Ahn, J.O.; Youn, H.Y. Canine mesenchymal stem cells treated with TNF- $\alpha$ and IFN- $\gamma$ enhance anti-inflammatory effects through the COX-2/PGE2 pathway. Res. Vet. Sci. 2018, 119, 19-26. [CrossRef] [PubMed]

114. Wang, B.; Lin, Y.; Hu, Y.; Shan, W.; Liu, S.; Xu, Y.; Zhang, H.; Cai, S.; Yu, X.; Cai, Z.; et al. mTOR inhibition improves the immunomodulatory properties of human bone marrow mesenchymal stem cells by inducing COX-2 and PGE2. Stem Cell Res. Ther. 2017, 8, 1-13. [CrossRef]

115. Kim, D.S.; Lee, W.H.; Lee, M.W.; Park, H.J.; Jang, I.K.; Lee, J.W.; Sung, K.W.; Koo, H.H.; Yoo, K.H. Involvement of TLR3-Dependent PGES Expression in Immunosuppression by Human Bone Marrow Mesenchymal Stem Cells. Stem Cell Rev. Rep. 2018, 14, $286-293$. [CrossRef]

116. Das, U.N. Bioactive Lipids as Mediators of the Beneficial Action(s) of Mesenchymal Stem Cells in COVID-19. Aging Dis. 2020, 11, 746-755. [CrossRef]

117. Bai, Y.; Wang, J.; He, Z.; Yang, M.; Li, L.; Jiang, H. Mesenchymal stem cells reverse diabetic nephropathy disease via lipoxin A4 by targeting transforming growth factor $\beta$ (TGF- $\beta$ )/smad pathway and pro-Inflammatory cytokines. Med. Sci. Monit. 2019, 25, 3069-3076. [CrossRef]

118. Speert, D.P.; Wannamaker, L.W.; Gray, E.D.; Clawson, C.C. Bactericidal Effect of Oleic Acid on Group A Streptococci: Mechanism of Action. Infect. Immun. 1979, 26, 1202-1210. [CrossRef] [PubMed]

119. Juers, J.A.; Rogers, R.M.; McCurdy, J.B.; Cook, W.W. Enhancement of bactericidal capacity of alveolar macrophages by human alveolar lining material. J. Clin. Investig. 1976, 58, 271-275. [CrossRef] [PubMed]

120. Nieman, C. Influence of trace amounts of fatty acids on the growth of microorganisms. Bacteriol. Rev. 1954, 18, 147-162. [CrossRef]

121. Kabara, J.J.; Swieczkowski, D.M.; Conley, A.J.; Truant, J.P. Fatty Acids and Derivatives as Antimicrobial Agents. Antimicrob. Agents Chemother. 1972, 2, 23-28. [CrossRef] [PubMed]

122. Larsson, K.; Norén, B.; Odham, G. Antimicrobial Effect of Simple Lipids with Different Branches at the Methyl End Group. Antimicrob. Agents Chemother. 1975, 8, 742-750. [CrossRef]

123. Heczko, P.B.; Lütticken, R.; Hryniewicz, W.; Neugebauer, M.; Pulverer, G. Susceptibility of Staphylococcus aureus and group A, B, C, and G streptococci to free fatty acids. J. Clin. Microbiol. 1979, 9, 333-335. [CrossRef] [PubMed]

124. Wyss, O.; Ludwig, B.J.; Joiner, R.R. The fungistatic and fungicidal action of fatty acids and related compounds. Arch. Biochem. $1945,7,415-424$.

125. Stock, C.C.; Francis, T., Jr. The inactivation of the virus of epidemic influenza by soaps. J. Exp. Med. 1940, 71, 661-681. [CrossRef]

126. Sands, J.; Auperin, D.; Snipes, W. Extreme Sensitivity of Enveloped Viruses, Including Herpes Simplex, to Long-Chain Unsaturated Monoglycerides and Alcohols. Antimicrob. Agents Chemother. 1979, 15, 67-73. [CrossRef] [PubMed]

127. Kohn, A.; Gitelman, J.; Inbar, M. Unsaturated free fatty acids inactivate animal enveloped viruses. Arch. Virol. 1980, 66, 301-307. [CrossRef] [PubMed]

128. Horowitz, B.; Piët, M.P.; Prince, A.M.; Edwards, C.A.; Lippin, A.; Walakovits, L.A. Inactivation of lipid-enveloped viruses in labile blood derivatives by unsaturated fatty acids. Vox Sang. 1988, 54, 14-20. [CrossRef]

129. Das, U.N. Anti-biotic-like action of essential fatty acids. Can. Med. Assoc. J. 1985, 132, 1350.

130. Das, U.N. Do unsaturated fatty acids function as endogenous anti-bacterial and anti-viral molecules? Am. J. Clin. Nutr. 2006, 83, 390-391. [CrossRef] [PubMed]

131. Das, U. Can essential fatty acid deficiency predispose to AIDS? Can. Med. Assoc. J. 1985, 132, 900-902.

132. Das, U.N. Essential fatty acids and acquired immunodeficiency syndrome. Med. Sci. Monit. 2005, 11, RA206-RA211.

133. Das, U.N. Arachidonic acid and other unsaturated fatty acids and some of their metabolites function as endogenous antimi-crobial molecules: A review. J. Adv. Res. 2018, 11, 57-66. [CrossRef] [PubMed]

134. Sheu, C.W.; Konings, W.N.; Freese, E. Effects of Acetate and Other Short-Chain Fatty Acids on Sugar and Amino Acid Uptake of Bacillus subtilis. J. Bacteriol. 1972, 111, 525-530. [CrossRef] [PubMed]

135. Ingram, L.O.; Eaton, L.C.; Erdos, G.W.; Tedder, T.F.; Vreeland, N.L. Unsaturated fatty acid requirement in Escherichia coli. Mechanism of palmitate-induced inhibition of growth by strain WN1. J. Membr. Biol. 1982, 1982, 31-40. [CrossRef] [PubMed]

136. Fay, J.P.; Farías, R.N. Inhibitory action of a non-metabolizable fatty acid on the growth of Escherichia coli: Role of metabolism and outer membrane integrity. J. Bacteriol. 1977, 132, 790-795. [CrossRef]

137. Norris, P.; Arnardottir, H.; Sanger, J.M.; Fichtner, D.; Keyes, G.S.; Serhan, C.N. Resolvin D3 multi-level proresolving actions are host protective during infection. Prostaglandins Leukot. Essent. Fat. Acids 2018, 138, 81-89. [CrossRef]

138. Das, U.N. Can Bioactive Lipids Inactivate Coronavirus (COVID-19)? Arch. Med. Res. 2020, 51, 282-286. [CrossRef]

139. Das, U.N. Can Bioactive Lipid Arachidonic Acid Prevent and Ameliorate COVID-19? Medicina (Kaunas) 2020, 56, 418. [CrossRef] [PubMed]

140. Das, U.N. Bioactive Lipids in COVID-19-Further Evidence. Arch. Med. Res. 2021, 52, 107-120. [CrossRef] 
141. Das, U.N. Essential fatty acids and their metabolites in the pathobiology of (coronavirus disease 2019) COVID-19. Nutrition 2020, 82, 111052. [CrossRef]

142. Toelzer, C.; Gupta, K.; Yadav, S.K.N.; Borucu, U.; Davidson, A.D.; Kavanagh Williamson, M.; Shoemark, D.K.; Garzoni, F.; Staufer, O.; Milligan, R.; et al. Free fatty acid binding pocket in the locked structure of SARS-CoV-2 spike protein. Science 2020, 370, 725-730. [CrossRef]

143. Goc, A.; Niedzwiecki, A.; Rath, M. Polyunsaturated $\omega-3$ fatty acids inhibit ACE2-controlled SARS-CoV-2 binding and cellular entry. Sci. Rep. 2021, 11, 5207. [CrossRef]

144. Shen, B.; Yi, X.; Sun, Y.; Bi, X.; Du, J.; Zhang, C.; Quan, S.; Zhang, F.; Sun, R.; Qian, L.; et al. Proteomic and Metabolomic Characterization of COVID-19 Patient Sera. Cell 2020, 182, 59-72. [CrossRef]

145. Yan, B.; Chu, H.; Yang, D.; Sze, K.-H.; Lai, P.-M.; Yuan, S.; Shuai, H.; Wang, Y.; Kao, R.Y.-T.; Chan, J.F.-W.; et al. Characterization of the Lipidomic Profile of Human Coronavirus-Infected Cells: Implications for Lipid Metabolism Remodeling upon Coronavirus Replication. Viruses 2019, 11, 73. [CrossRef]

146. Liu, T.; Yang, Q.; Cao, Y.-J.; Yuan, W.-M.; Lei, A.-H.; Zhou, P.; Zhou, W.; Liu, Y.-D.; Shi, M.-H.; Yang, Q.; et al. Cyclooxygenase-1 Regulates the Development of Follicular Th Cells via Prostaglandin E2. J. Immunol. 2019, 203, 864-872. [CrossRef]

147. Duan, Y.-Q.; Xia, M.-H.; Ren, L.; Zhang, Y.-F.; Ao, Q.-L.; Xu, S.-P.; Kuang, D.; Liu, Q.; Yan, B.; Zhou, Y.-W.; et al. Deficiency of Tfh Cells and Germinal Center in Deceased COVID-19 Patients. Curr. Med. Sci. 2020, 40, 618-624. [CrossRef] [PubMed]

148. Garvin, M.R.; Alvarez, C.; Miller, J.I.; Prates, E.T.; Walker, A.M.; Amos, B.K.; Mast, A.E.; Justice, A.; Aronow, B.; Jacobson, D.A. A mechanistic model and therapeutic interventions for COVID-19 involving a RAS-mediated bradykinin storm. eLife 2020, 9 , e59177. [CrossRef] [PubMed]

149. Candelario, J.; Chachisvilis, M. Activity of Bradykinin B2 Receptor Is Regulated by Long-Chain Polyunsaturated Fatty Acids. PLoS ONE 2013, 8, e68151. [CrossRef]

150. Mann, E.R.; Menon, M.; Knight, S.B.; Konkel, J.E.; Jagger, C.; Shaw, T.N.; Krishnan, S.; Rattray, M.; Ustianowski, A.; Bakerly, N.D.; et al. Longitudinal immune profiling reveals key myeloid signatures associated with COVID-19. Sci. Immunol. 2020, 5, 6197. [CrossRef]

151. Arnardottir, H.H.; Dalli, J.; Colas, R.A.; Shinohara, M.; Serhan, C.N. Aging delays resolution of acute inflammation in mice: Repro-gramming the host response with novel nano-proresolving medicines. J. Immunol. 2014, 193, 4235-4244. [CrossRef] [PubMed]

152. Chiscano-Camón, L.; Ruiz-Rodriguez, J.C.; Ruiz-Sanmartin, A.; Roca, O.; Ferrer, R. Vitamin C levels in patients with SARS-CoV-2associated acute respiratory distress syndrome. Crit. Care 2020, 24, 522. [CrossRef]

153. Gardiner, N.; Duncan, J. Enhanced prostaglandin synthesis as a mechanism for inhibition of melanoma cell growth by ascorbic acid. Prostaglandins Leukot. Essent. Fat. Acids 1988, 34, 119-126. [CrossRef]

154. Srivastava, K. Ascorbic acid enhances the formation of prostaglandin E1 in washed human platelets and prostacyclin in rat aortic rings. Prostaglandins Leukot. Med. 1985, 18, 227-233. [CrossRef]

155. Kotani, N.; Hashimoto, H.; Kushikata, T.; Yoshida, H.; Muraoka, M.; Takahashi, S.; Matsuki, A. Intraoperative prostaglandin E1 improves antimicrobial and inflammatory responses in alveolar immune cells. Crit. Care Med. 2001, 29, 1943-1949. [CrossRef] [PubMed]

156. Das, U.N. Is insulin an anti-inflammatory molecule? Nutrition 2001, 17, 409-413. [CrossRef]

157. Das, U.N. Possible beneficial action(s) of glucose-insulin-potassium regimen in acute myocardial infarction and inflammatory conditions: A hypothesis. Diabetologia 2000, 43, 1081-1082. [PubMed]

158. Li, J.; Zhang, H.; Wu, F.; Nan, Y.; Ma, H.; Guo, W.; Wang, H.; Ren, J.; Das, U.N.; Gao, F. Insulin inhibits tumor necrosis factor-alpha induction in myocardial ische-mia/reperfusion: Role of Akt and endothelial nitric oxide synthase phosphorylation. Crit. Care Med. 2008, 36, 1551-1558. [CrossRef] [PubMed]

159. Bellenger, J.; Bataille, A.; Massey, K.A.; Nicolaou, A.; Rialland, M.; Tessier, C.; Kang, J.X.; Narce, M. High Pancreatic n-3 Fatty Acids Prevent STZ-Induced Diabetes in Fat-1 Mice: Inflammatory Pathway Inhibition. Diabetes 2011, 60, 1090-1099. [CrossRef] 